\title{
Metal Nanoparticle-Microbe Interactions: Synthesis and Antimicrobial Effects
}

\author{
Mujeebur R. Khan,* Katharina M. Fromm,* Tanveer F. Rizvi, Bernd Giese, \\ Faheem Ahamad, Raymond J. Turner, Michael Füeg, and Enrico Marsili
}

\begin{abstract}
Metal nanoparticles (NPs), chalcogenides, and carbon quantum dots can be easily synthesized from whole microorganisms (fungi and bacteria) and cell-free sterile filtered spent medium. The particle size distribution and the biosynthesis time can be somewhat controlled through the biomass/metal solution ratio. The biosynthetic mechanism can be explained through the ionreduction theory and UV photoconversion theory. Formation of biosynthetic NPs is part of the detoxification strategy employed by microorganisms, either in planktonic or biofilm form, to reduce the chemical toxicity of metal ions. In fact, most reports on NP biosynthesis show extracellular metal ion reduction. This is important for environmental and industrial applications, particularly in biofilms, as it allows in principle high biosynthetic rates. The antimicrobial and antifungal effect on biosynthetic NPs can be explained in terms of reactive oxygen species and can be enhanced by the capping agents attached to the NP during the biosynthesis process. Industrial applications of NP biosynthesis are still lagging, due to the difficulty of controlling NP size and low titer. Further, the environmental assessment of biosynthetic NPs has not yet been carried out. It is expected that further advancements in biosynthetic NP research will lead to applications, particularly in environmental biotechnology.
\end{abstract}

metal solution, reduction of the metal ions leads to the generation of metal atom clustering generating nanosized particles. A characteristic of biosynthetic NPs is their high stability as the organisms provide their own biomolecular capping agent(s). ${ }^{[1]}$

While plant-based production of NPs is now considered a scientific curiosity rather than a promising biotechnology, ${ }^{[2]}$ bacteriamediated NP biosynthesis offers better chances, in light of the poorly characterized microbial diversity and the complex chemistry of enzymes in metal-reducing bacteria. Two recent works focused on directed biofabrication of CdSe-nanoparticles through regulating extracellular electron transfer ${ }^{[3]}$ and the biosynthesis of highly active copper NPs (CuNP) by Shewanella oneidensis. ${ }^{[4]}$ However, the description of molecular mechanism(s) involved in the biosynthesis of NPs has received little attention, which is the focus of this review.

\section{Introduction}

In view of the increasing applications and demand of nanomaterials, synthesis of nanoparticles (NPs) mediated by microorganisms can be adopted once the method is commercially explored and the underlying molecular mechanisms are fully understood. To synthesize metal atom NPs, an aqueous solution of a metal salt, for example, $\mathrm{AgNO}_{3}$ for silver NPs (AgNPs) and $\mathrm{AuCl}_{4}$ for gold NPs (AuNPs), is prepared. Thereafter, the microbial culture, cell extract, or sterile filtrate is mixed with this

Prof. M. R. Khan, T. F. Rizvi, Dr. F. Ahamad

Department of Plant Protection

Faculty of Agricultural Sciences

Aligarh Muslim University

Aligarh 202002, India

E-mail: mrkhan.pp@amu.ac.in

Prof. K. M. Fromm, Prof. B. Giese

Department of Chemistry

University of Fribourg

Chemin du Musée 9, Fribourg 1700, Switzerland

E-mail: katharina.fromm@unifr.ch

The ORCID identification number(s) for the author(s) of this article can be found under https://doi.org/10.1002/ppsc.201900419.

\section{Microbial Synthesis of Metal Nanoparticles}

\subsection{Silver}

\subsubsection{Use of Cell-Free Culture Filtrates and Extracts (CFCF)}

The CFCF or culture supernatants (CS) of bacteria mediate the synthesis of $\mathrm{AgNPS}^{[5]}$ as presented in this section. The CFCF from the family Enterobacteriaceae reduce silver ions to AgNPs (Table 1). CFCF of Klebsiella pneumoniae, Escherichia coli, and

Prof. R. J. Turner

Department of Biological Sciences

Faculty of Science

University of Calgary

Calgary, Alberta T2N1N4, Canada

Dr. M. Füeg

Chemical Engineering Department

University of Alcalá

Alcalá de Henares 28871, Spain

Prof. E. Marsili

Department of Chemical and Materials Engineering

Nazarbayev University

53 Kabanbay Batyr Avenue, Nur-Sultan 010000, Kazakhstan 
Enterobacter cloacae reduced silver ions from $\mathrm{AgNO}_{3}$ to $\mathrm{AgNPs}$ within 5 min. ${ }^{[6]}$ In another study, AgNPs were synthesized by adding the supernatant of an E. coli culture to a solution of $\mathrm{AgNO}_{3} .{ }^{\left[{ }^{7]}\right.}$ Singh et al. reported the bacteria Brevibacterium frigoritolerans DC2 induced extracellular synthesis of AgNPs. ${ }^{\left[{ }^{8]}\right.}$ Similarly, culture filtrate of Pichia fermentans JA2, a bacterial strain isolated from spoiled fruit pulp mediated the synthesis of silver and zinc oxide NPs (ZnO NPs) extracellularly. ${ }^{[9]}$

Studies have shown that the microbial NP synthesis is strongly influenced by the type of CFCF, its concentration, $\mathrm{pH}$, and temperature which gives the possibility to control the size and shape of the formed AgNPs. For example, the CFCF of A. kerguelensis failed to synthesize the AgNPs at $37^{\circ} \mathrm{C}$, while $P$. antarctica mediated the AgNP synthesis at this temperature. ${ }^{[30]}$ The CFCF of $B$. flexus S-27 has been reported to mediate the AgNP synthesis in an aqueous silver nitrate solution, and yielded anisotropic AgNPs of spherical and triangular shape, measuring 12 and $65 \mathrm{~nm}$ in size, respectively. ${ }^{[31]}$ The culture filtrate of Pseudomonas aeruginosa, Arthrobacter kerguelensis, A. gangotriensis, $P$. antarctica, $P$. meridiana, $P$. proteolytica (psychrophilic bacteria), Bacillus cecembensis, and B. indicus (mesophilic bacteria) successfully induced the extracellular synthesis of AgNPs of 6-13 nm size at reaction temperatures of 7 and $22{ }^{\circ} \mathrm{C}^{[30]}$ The AgNPs remained stable up to eight months in a suspension stored in the dark, indicating effective biocapping that prevents aggregation.

\subsubsection{Bacterial Biomass}

The bacterial cells separated from the fermentation broth have also been used to synthesize AgNPs (Table 2). The bacterium $B$. licheniformis mediates the biosynthesis of $50 \mathrm{~nm}$ sized AgNPs at $\mathrm{pH} 7$ and $37^{\circ} \mathrm{C} .{ }^{[32]}$ Law et al. reported that silver ions in the form of $\mathrm{AgCl}$ were reduced to insoluble AgNPs when the culture of Geobacter sulfurreducens was added to the solution. ${ }^{[33]}$ They proposed that AgNPs were precipitated extracellularly, a reaction depending on c-type cytochromes (see also Section 3.3.5). The authors propose to exploit this process to recover AgNPs from contaminated water.

\subsubsection{Fungus-Mediated Biosynthesis of Silver Nanoparticles}

Many fungal strains have been tested to mediate the synthesis of AgNPs. However, in contrast to bacteria, in most cases only the fungal biomass has been used to synthesize the NPs, whereas the culture filtrates have been scarcely explored, as shown next.

Fungal Biomass: The biomass (liquid cultures) of several plant pathogenic, saprophytic, and mycoparasitic fungi have been reported to reduce silver ions to AgNPs from an aqueous $\mathrm{AgNO}_{3}$ solution (Table 1). ${ }^{[12,14,15,42,43]}$ The biomass of Aspergillus niger generated AgNPs from silver nitrate at $25^{\circ} \mathrm{C}$ in the dark after a pretreatment including incubation, washing and filtration. ${ }^{[12]}$ Vahabi et al. achieved the formation of 5-50 nm diameter spherical AgNPs using the culture of Trichoderma reesei..$^{[4]}$ For this, the fungus was first grown in glucose casein medium at $25-28{ }^{\circ} \mathrm{C}$ under continuous mixing conditions at $150 \mathrm{rpm}$ for

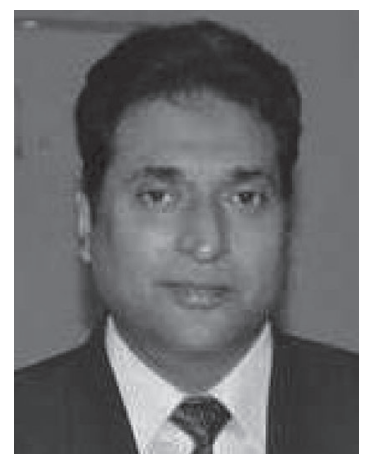

Mujeebur Rahman Khan completed a M.Sc. (1984) and Ph.D. (1988) in plant pathology and nematology from Aligarh Muslim University, India. He worked as a postdoc at North Carolina State University-USA, CDFA, California-USA, and Institute of Parasitology, CAB-UK. He joined AMU as a faculty member in 1993 and is presently serving as professor in the Department of Plant Protection. His research areas include plant-microbe interaction, microbial control of pathogenic fungi and nematodes, plant diseases under climate change, and nanoparticle-plant/microbe interaction.

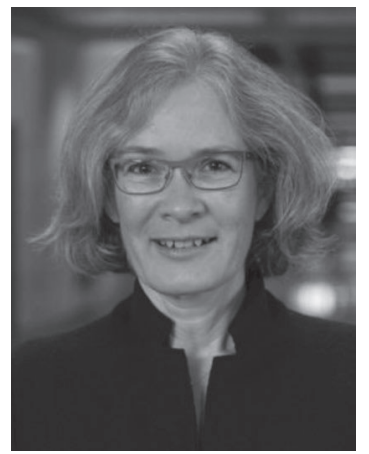

Katharina M. Fromm obtained her Ph.D. from the University of Karlsruhe, Germany, in 1994. After postdocs with, for example, Nobel Prize winner Jean-Marie Lehn in Strasbourg, France, she did her habilitation in Geneva, Switzerland. In 2003, she accepted a Swiss National Science Foundation-

Professorship at the University of Basel, before becoming full professor at the University of Fribourg, Switzerland, in 2006. Her research interests span from antimicrobial agents to nanomaterials for batteries.

$72 \mathrm{~h}$ and the settled mycelia were used for the AgNP synthesis. Fourier transform infrared spectroscopy imaging of the synthesized AgNPs showed the presence of fungal protein around the particles that is assumed to impart the stability to the NPs in the suspension. ${ }^{[44]}$ The cultures of Fusarium oxpsporum also induced reduction of silver ions to AgNPs of 5-15 nm in size. ${ }^{[45]}$ Interestingly, the fungus synthesized both tryptophan and tyrosine, which likely increase the stability of the particles in the solution. The role of aromatic amino acids will be further discussed in Section 3.3.

Fungal Culture Filtrate: The cell-free culture filtrate/supernatant of fungi has also been used to synthesize AgNPs (Table 1). For example, AgNPs were formed when CFCF of a fungus, Pleurotus ostreatus, was added to an $\mathrm{AgNO}_{3}$ solution. ${ }^{[46]}$ The reaction was carried out in darkness and 6-23 $\mathrm{nm}$ AgNPs were formed within $72 \mathrm{~h}$. The synthesis of AgNPs was optimized for F. solani and $\mathrm{AgNO}_{3}$ yielding AgNPs of 8-15 nm diameter at $25^{\circ} \mathrm{C}$ after $24 \mathrm{~h} .{ }^{[47]}$

Based on these studies, Fusarium, Aspergillus, and Trichoderma species may be exploited for the commercial synthesis of AgNPs. However, the relative performance of different strains/ isolates of these fungi is influenced by factors like solution concentration, $\mathrm{pH}$, temperature, etc., and require individual 
Table 1. Fungi-catalyzed synthesis of nanoparticles and antimicrobial effects of NPs.

\begin{tabular}{|c|c|c|c|c|c|}
\hline \multicolumn{3}{|c|}{ Synthesis of nanoparticles } & \multicolumn{2}{|l|}{ Antimicrobial effects } & \multirow[t]{2}{*}{ Ref. } \\
\hline Metal & Size $[\mathrm{nm}]$ & Synthesized by & Target microorganism & Zone of inhibition $[\mathrm{mm}]$ & \\
\hline $\mathrm{Ag}$ & - & Agaricus bisporus & $\begin{array}{l}\text { Escherichia coli, Klebsiella sp., Pseudomonas sp., Enterobacter sp., Proteus sp., } \\
\text { Staphylococcus aureus, Salmonella typhi, S. paratyphi }\end{array}$ & $14-22$ & [10] \\
\hline $\mathrm{Ag}$ & $5-30$ & Aspergillus flavus & $\begin{array}{l}\text { E. coli, S. aureus, Micrococcus luteus, Enterococcus faecalis, P. aeruginosa, } \\
\text { Acinetobacter baumannii, K. pneumoniae, Bacillus spp. }\end{array}$ & $14-15$ & [11] \\
\hline $\mathrm{Ag}$ & 20 & A. niger, A. fumigatus & P. aeruginosa, S. aureus, Salmonella typhae, E. coli & $16-28$ & [12] \\
\hline \multirow[t]{2}{*}{$\mathrm{Ag}$} & $55-73$ & Bipolaris tetramera & A. niger, Trichoderma sp., E. coli, S. aureus, B. cerus & $12-14$ & [13] \\
\hline & & & B. subtilis, P. erogens & $7-8$ & \\
\hline $\mathrm{Ag}$ & $5-50$ & Corynebacterium glutamecum & - & - & [14] \\
\hline $\mathrm{Ag}$ & $25-75$ & $\begin{array}{l}\text { Corelus versicolor, } P \text {. bravicom- } \\
\text { pactum, P. fellutanum }\end{array}$ & - & - & {$[14,15]$} \\
\hline $\mathrm{Ag}$ & $30-70$ & Cryphonectria sp. & S. aureus (ATCC-25923), S. typhae (ATCC-51812), E. coli (ATCC-39403) & $12-16$ & [16] \\
\hline \multirow[t]{3}{*}{$\mathrm{Ag}$} & 78 & Fusarium oxysporum & S. aureus (MRSA101), S. aureus (MRSA107) & $500 \times 10^{-6} \mathrm{M}$ & [17] \\
\hline & & & E. coli (ESBL176), E. coli (ESBL 192) & $250 \times 10^{-6} \mathrm{M}$ & \\
\hline & & & $\begin{array}{l}\text { E. coli (ESBL167), E. coli (KPC131), E. coli (ESBL 169), E. coli (KPC133), } \\
\text { A. baumannii (CRO1) }\end{array}$ & $125 \times 10^{-6} \mathrm{M}$ & \\
\hline $\mathrm{Ag}$ & 25 & F. solani, F. oxysporum & - & - & [18] \\
\hline $\mathrm{Ag}$ & $16-70$ & F. oxysporum NGD & Enterobacter sp., P. aeruginosa, K. pneumoniae, E. coli & $19-31$ & [19] \\
\hline $\mathrm{Ag}$ & $5-40$ & Macrophomina phaseolina & E. coli (DH5 $\alpha$-MDR), Agrobacterium tumefaciens (LBA4404-MDR) & $3.0-3.3$ & [20] \\
\hline $\mathrm{Ag}$ & $10-15$ & Penicilium polonicum & A. baumanii & 21.2 & [21] \\
\hline $\mathrm{Au}$ & $20-25$ & Phoma glumerulata & - & - & {$[22]$} \\
\hline $\mathrm{Ag}$ & $27-50$ & Rhizoppus spp. & E. coli & $15-22$ & [23] \\
\hline $\mathrm{Ag}$ & $5-50$ & Tricholoma crassum & E. coli (DH5 $\alpha)$, A. tumifaciens (LBA4404) & $18-20$ & [24] \\
\hline $\mathrm{Ag}$ & $1-50$ & Trichoderma Viride & A. baumanai, Schigella sonnei, S. boybii, S. typhaemurium & $20-28$ & {$[25]$} \\
\hline $\mathrm{Ag}$ & $5-40$ & T. viride & E. coli, S. typhi, S. aureus, M. luteus & $16-36$ & [26] \\
\hline $\mathrm{Zn}$ & - & - & P. aerogenosa & 22 & [27] \\
\hline $\mathrm{Cu}$ & - & - & S. aureus, E. coli & $1.1-1.7$ & [28] \\
\hline $\mathrm{Ag}$ & 15 & Volvariella volvacea & - & - & {$[22]$} \\
\hline $\mathrm{Ti}$ & $5-28$ & F. oxysporum & Aspergillus niger & - & [29] \\
\hline
\end{tabular}

optimization of the NP yields. Furthermore, the chemical identity of the reducing agents or biochemical mechanisms involved remained largely unknown.

\subsection{Gold}

Some fungi, bacteria, and yeasts have been used to synthesize AuNPs. Synthesis of AuNPs in good yield was achieved with the Thermomonospora sp., an extremophilic bacteria. ${ }^{[4]}$ Shewanella sp., synthesized AuNPs using $\mathrm{H}_{2}$ as an electron donor. ${ }^{[49]}$ Rhodopseudomonas capsulate produced 10-20 $\mathrm{nm}$ size AuNPs. ${ }^{[50]}$ The supernatant of $P$. aeruginosa culture reduced the gold ions extracellularly ${ }^{[1]}$ whereas G. sulfurreducens formed the NPs intracellularly. ${ }^{[52]}$ Synthesis of AuNPs has also been found efficiently mediated by the fungi Collitotrichum sp., ${ }^{[3]}$ Volvariella volvacea ${ }^{[22]}$ as well as Verticillium spp. ${ }^{[54]}$

A few yeasts have been found equally effective in synthesizing AuNPs. The biomass of Pichia jadinii was added to the aqueous gold solutions of different concentrations, and AuNPs were synthesized intracellularly. The NPs were of triangular, hexagonal, and spherical shape with an average diameter of $100 \mathrm{~nm}$. Both biomass and yeast extract yielded AuNPs within $24 \mathrm{~h}$ after careful pretreatment. ${ }^{[55]}$ In addition to the cell wall components, the proteins released by the yeast cells are apparently involved in the formation of AuNPs and in their stabilization. ${ }^{[56]}$ Lengke et al. used a CFCF of cyanobacterium Plectonema boryanum to synthesize AuNPs of 10-25 nm size. ${ }^{[57]}$

\subsection{Platinum and Palladium}

Extracellular synthesis of PtNPs was achieved by using biomass of F. oxysporum to produce 5-30 nm size NPs. ${ }^{[58]}$ Metal ion-reducing bacterium, Shewanella algae has also been found to produce platinum nanoparticles (PtNPs). ${ }^{[59]}$ The cell suspension of $S$. algae under a $\mathrm{N}_{2}-\mathrm{CO}_{2}(80: 20, \mathrm{v} / \mathrm{v})$ atmosphere reduced aqueous $\left[\mathrm{PtCl}_{6}\right]^{2-}$ ions to PtNPs of $5 \mathrm{~nm}$ size, largely formed on the surface of the bacterial endospore (Figure 1). Brayner et al. have reported the synthesis of palladium and platinum NPs by adding the cyanobacteria Anabaena, Calothrix, and Leptolyngbya to solutions containing these metal ions. The 
Table 2. Selected examples of bacteria-catalyzed synthesis of NPs and antimicrobial effects of NPs.

\begin{tabular}{|c|c|c|c|c|}
\hline \multicolumn{2}{|c|}{ Synthesis of silver nanoparticles } & \multicolumn{2}{|l|}{ Antimicrobial effects } & \multirow[t]{2}{*}{ Ref. } \\
\hline Size $[\mathrm{nm}]$ & Synthesized by & Target microorganism & Zone of inhibition [mm] & \\
\hline $8-16$ & Aeromonas sp. THG-FG1.2 & $\begin{array}{c}\text { Bacillus cereus (ATCC14579), B. subtilis (KACC14741), Staphylococcus aureus } \\
\text { (ATCC6538), Escherichia coli (ATCC10798), Pseudomonas aeruginosa (ATCC6538), Vibrio } \\
\text { parahaemolyticus (ATCC 33844), Salmonella enterica (ATCC13076), Candida albicans } \\
\text { (KACC30062), C. tropicalis (KCTC7909) }\end{array}$ & $11-20$ & [34] \\
\hline $10-50$ & Anabaena diololum & $\begin{array}{c}\text { Klebsiella pneumoniae DF12SA (HQ114261), E. coli DF39TA (HQ163793), S. aureus } \\
\text { DF8TA (JN642261) }\end{array}$ & $33-36$ & [35] \\
\hline $24-46$ & Bacillus cereus & E. coli, S. aureus, K. pneumoniae, P. aeruginosa & $14-23$ & [36] \\
\hline $5-95$ & Bacillus safensis (LAU13) & E. coli, K. granulomatis, P. vulgaris, P. aeruginosa, S. aureus & $11-19$ & \\
\hline 50 & B. lichenoformis & - & - & [32] \\
\hline $14-42$ & Bacillus sp. & $\begin{array}{l}\text { Staphylococcus epidermidis strain } 73 \text { (pus), S. epidermidis strain 145, S. epidermidis strain } \\
\text { 152, S. aureus (MTCC87), Salmonella typhi, S. paratyphi, Vibrio cholerae (MTCC3906) }\end{array}$ & 13-19 & [37] \\
\hline- & E. coli & K. pneumoniae, $P$. aeruginosa, S. aureus & 14-19 & [38] \\
\hline $6-13$ & $\begin{array}{l}\text { E. coli, P. antarctica, A. kurkulensis, } \\
\text { Bacillus sp., Pseudomons sp. }\end{array}$ & P. antatctica, B. indicus, P. protolotica, E. coli, Arthrobacter curgulenses, A. gangotriansis & - & [30] \\
\hline 30 & Geobacter sulfurreducens & - & - & [33] \\
\hline 100 & Streptacidiphilus durhamensis & E. coli, K. pneumoniae, S. aureus, B. subtilis, P. aeruginosa & $6-10$ & [39] \\
\hline $20-70$ & Streptomyces & K. pneumoniae (ATCC100603), K. pneumoniae, E. coli, Citrobacter & $2-4 \mu \mathrm{gLL}^{-1}$ & [40] \\
\hline $23-48$ & Streptomyces sp. GUT21 & E. coli (MTCC 9537), K. pneumoniae (MTCC109), S. aureus (MTCC96) & $27-29$ & [41] \\
\hline & & P. aeruginosa (MTCC1688) & 10 & \\
\hline
\end{tabular}

NPs were produced intracellularly in the substrate, and the polysaccharides synthesized by the cyanobacteria were suggested to help in the stabilization and easy recovery of the NPs. ${ }^{[60]}$

\subsection{Copper}

To date, CuNPs have been mostly produced biogenically using various plant ${ }^{[61]}$ and fruit extracts. ${ }^{[62]}$ Addition of P. stutzeri to $\mathrm{CuSO}_{4}$ solution yielded spherical CuNPs. In this study, it was recognized that the bacteria not only provided the reducing chemistry but also the organic capping layer. ${ }^{[63]}$ In another study, cell-free supernatant of P. fluorescens yielded CuNPs of

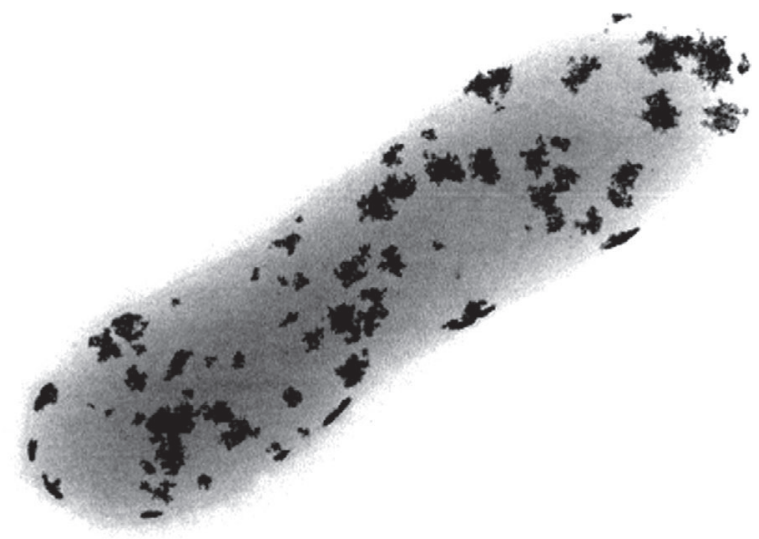

Figure 1. TEM image of platinum nanoparticles produced on the surface of the endospore of the bacteria, S. algae. Reproduced with permission. Copyright Prof. Yasuhiro Konishi, Department of Chemical Engineering, Osaka Prefecture University, Japan.
$49 \mathrm{~nm} \cdot{ }^{[64]}$ Kimber et al. concluded in their study that $S$. oneidensis facilitated the bioreduction of $\mathrm{Cu}^{2+}$ to elemental copper. Bioreduction of $\mathrm{Cu}^{2+}$ may valorize waste waters from mining and industries. ${ }^{[4]}$

\subsection{Base Metals}

Most base metal ions are generally not reduced to their zerovalent state and form binary metal compounds with nonmetals. Limited information is available on microbe-mediated NP synthesis of Zn-, U-, and Cd-containing NPs. The synthesis of zinc oxide nanoparticles with bacteria Aeromonas hydrophila was successfully achieved. ${ }^{[65]}$ The particles were crystal-like, oval, or spherical in shape, and on average $58 \mathrm{~nm}$ in size. Prasad and Jha used Lactobacillus sporogens for the synthesis of ZnO NPs (5-15 nm). ${ }^{[66]}$ In one of the first early studies, CFCF of Micrococcus lactilyticus synthesized uranium oxide NPs by the reduction of hexavalent uranium ions to tetravalent uraninite NPs. ${ }^{[67]}$

The synthesis of cadmium sulfide NPs (CdS NPs) has been reported by using microbial biomass of yeasts, Candida glubrata and Schizosaccharomyces pombe. ${ }^{[68]}$ The yeasts induced the formation of a metal-thiolate complex with phytochelatins, which yielded spherical CdS NPs. Sweeney et al. used E. coli to synthesize CdS NPs of 2-5 nm size. ${ }^{[69]}$ Prasad and Jha also synthesized CdS NPs by using Lactobacillus spp., ${ }^{[70]}$ while Cunningham and Lundie used Clostridium thermoaceticum. ${ }^{[1]}$ The wilt fungus $F$. oxpsporum was found to mediate the biosynthesis of cadmium selenide NPs. ${ }^{\text {[2] }}$

Bansal et al. demonstrated that synthesis of titanium dioxide particles $\left(\mathrm{TiO}_{2}\right)$ can be achieved by using the biomass of F. oxpsporum. ${ }^{[73]}$ A method for producing size-controlled 
magnetite $\left(\mathrm{Fe}_{3} \mathrm{O}_{4}\right)$ NPs through the reduction of $\mathrm{Fe}^{3+}$ minerals by the anaerobic G. sulfurreducens was also demonstrated. ${ }^{[74]}$ The average particle size and distribution was regulated by adjusting the amount of the whole-cell biocatalyst introduced at the start of the reaction. The higher concentrations of bacteria yielded particles with smaller size and a narrower size distribution. Higher biomass concentrations are thought to accelerate the higher nucleation rates due to an increase in $\mathrm{Fe}^{2+}$ availability that resulted in the production of smaller magnetite NPs.

\subsection{Carbon Quantum Dots (CDs)}

Carbon quantum dots are carbon NPs $(<10 \mathrm{~nm})$ and may contain other elements like hydrogen and oxygen. ${ }^{[75]}$ The superior characteristics for biocompatibility, water dispersity, and photostability make the CDs an attractive photoluminescent material. ${ }^{[6]}$ CDs have broad applications in medicine especially in drug delivery and photothermal therapy. Further, CDs also have potential use as bioimagers and biosensors. ${ }^{[77]}$ The CDs exhibit various surface passivation schemes, ${ }^{[78,79]}$ chemical functionalization with organic molecules, ${ }^{[79,80]}$ and may show the quantumconfinement effect. ${ }^{[1,82]}$ Moreover, the CDs exhibit photoexcited properties and redox processes, which resemble conventional nanoscale semiconductors, for example, photoinduced charge formation of electrons and holes (radical anions and cations) and their fluorescence emissions. ${ }^{\text {[79,81] }}$ The photogenerated radical anions and cations by carbon dots can catalyze various processes ${ }^{[81]}$ and are also responsible for strong photodynamic effects. ${ }^{[81,83]}$ The intrinsically nontoxic character makes the CDs highly advantageous and environment friendly. ${ }^{[84,85]}$ Generally, antibacterial chemicals present risks of environmental and human toxicity, ${ }^{[86]}$ but CDs cause antibacterial effects largely through the photoinduced redox processes. ${ }^{[85,87]}$

Liu et al. achieved the green synthesis of CDs utilizing some biomass from natural resources as a carbon source. ${ }^{[8]}$ The exopolysaccharide (EPS), a bacterial derived product and some bacteria have also been used as a molecular precursor (carbon source) for the CD synthesis. ${ }^{[89]}$ A simple and single-step hydrothermal method is commonly used to synthesize CDs from biomass. ${ }^{[90]}$ Using this method, the fluorescent N-doped CDs were synthesized from bacterial amino EPS. ${ }^{[89]}$ This CD synthesis involves hydrothermal reaction, which is a simple and single-step process and does not require any addition of a dopant or passivation agent. Lin et al. successfully used the amino EPS obtained during the fermentation of L. plantarum to synthesize carbon dots. ${ }^{[89]}$ To synthesize fluorescent CDs by a single-step process, B. cereus was used as a carbon source. ${ }^{[91]}$ Recently, Li et al. synthesized two types of luminescent carbon dots with the help of a hydrothermal process in which bacterial cellulose was used as a carbon source. ${ }^{[92]}$

\subsection{Characterization Methods}

Given the many different metallic or metal-containing nanoparticles that can be produced using microbes, their characterization and identification is crucial. Powder X-ray diffraction (PXRD) allows to identify the chemical phase of crystalline nanoparticles as well as their average crystallite size, independently if the nanoparticles are isolated or mixed with organic matter or cells/bacteria. Infrared (IR) and Raman spectroscopy are useful in cases where the nanoparticles exhibit vibrational features that can clearly be distinguished from the organic matter/cells. A method that can also be used in situ is UV-vis spectroscopy, which is helpful to analyze nanoparticle formation for colored species, e.g., metal NPs (based on their surface plasmon resonance) or quantum dots and allows to a certain extent to determine the size and shape of the nanoparticles, typically in suspension. ${ }^{[93,94]}$ Static (SLS) and dynamic light scattering (DLS) using laser light, X-rays, or neutrons on samples in suspension, as well as small angle X-ray scattering (SAXS) with frozen or dry samples can be useful tools to determine the particle size. ${ }^{[95]}$ This can, however, be tricky in the presence of organic matter or entire bacteria as, e.g., bacteria also contribute to the scattering phenomena. Electron microscopy (scanning and transmission, SEM and TEM) might help in these cases to analyze the particle size and composition further, and to also determine the position of the nanoparticles, e.g., if they are inside of a cell, on the membrane or outside. ${ }^{[96,97]}$ Since ultrahigh vacuum is typically required for electron microscopy techniques, it is important to take care that the entire (bacterial) cells remain intact (e.g., using cryo-methods), and do not "explode" during the sample preparation, as this may lead to false conclusions. ${ }^{[98]}$ These imaging techniques are suited to be combined with, e.g., electron diffraction and energy-dispersive X-ray spectroscopy (EDS). High-resolution TEM in combination with electron diffraction is useful to identify the compound composition and phase as well as if a particle is made of a single crystal or multiple crystallites, while the second may even provide the elemental distribution over a given area of a sample. Both methods, extremely helpful and complementary to the visual identification of nanoparticles, should be used to give proper proof of the sample, guaranteeing thereby that the particles seen via TEM or SEM are truly the desired and/ or expected ones. Additional X-ray photoelectron spectroscopy (XPS) may also provide information about the oxidation state of the chemical elements. In the specific case of silver and gold nanoparticles, surface-enhanced Raman spectroscopy might be useful in some cases in which the characterization of the compounds covering the nanoparticles (the corona, for example) is of interest. ${ }^{[99]}$ Atomic force microscopy is another tool to determine the size and shape of nanoparticles, although it is likely less precise than SEM or TEM and may be more useful in the context of surface topology. Gas sorption measurements will give insights into the porosity of the nanoparticles, which might be important for their biological behavior and properties related to transport. Further methods include the determination of the surface charge of nanoparticles after isolation from the synthesis mixture, elemental analysis techniques such as atomic absorption spectroscopy (AAS) or inductively coupled plasma mass spectrometry or optical emission spectroscopy (ICP-MS or ICP-OES), aerodynamic particle sizer (APS), and scanning mobility particle sizer (SMPS), both for airborne particles, or matrix-assisted laser desorption/ionization mass spectrometry (MALDI-MS). An excellent review also gives more exotic and advanced methods, which are not always easily accessible. ${ }^{100]}$ 

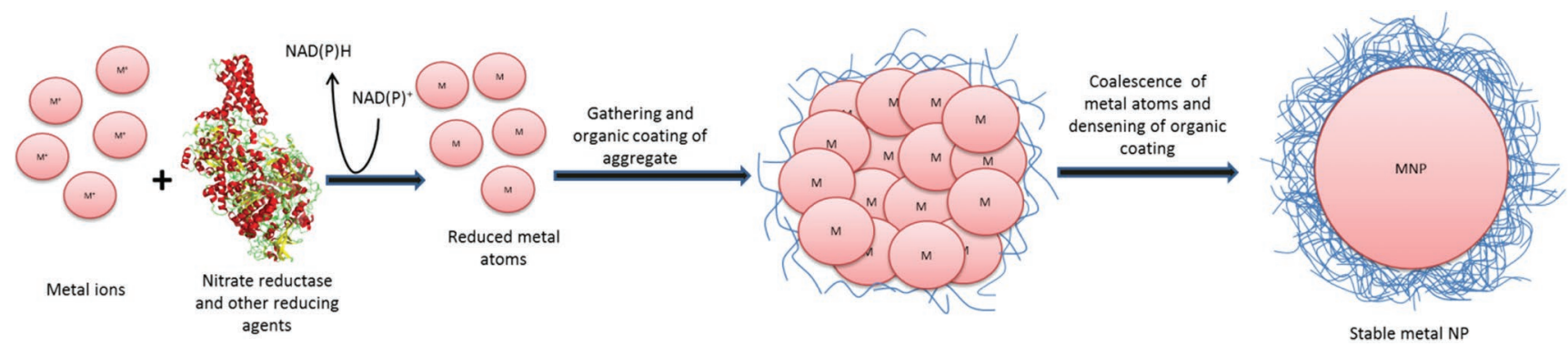

Figure 2. Simplified schematic representation of the microbial synthesis of metallic nanoparticles by the reduction mechanism. Adapted with permission. ${ }^{[238]}$ Copyright 2019, Wiley-VCH.

What becomes clear is that a single method usually gives only partial information on the nanoparticles and one should combine as many methods as possible for a full characterization.

\section{Mechanisms of Microbial Synthesis of Nanoparticles}

Although considerable research on the observation that microbes can synthesize NPs has been done, little effort has been made toward the understanding of this process, and most studies only postulate mechanisms. Common to all models are the following general steps after mixing bacteria/bacterial extracts with the metal ions: First, the metal ions tend to concentrate on or within the microbial cells. Thereafter, the ions are considered to be reduced to the zero-valence form leading to their aggregation into clusters of several atoms, which then further aggregate, eventually leading to nanosized stable particles. The initial reduction processes are likely by the action of enzyme(s) synthesized by the microorganism or their metabolites. In case of a cell-free culture supernatant or a filtrate, the ions are directly reduced by reducing agents stemming from the microbial metabolism. In fact, the knowledge on the mechanism of the microbial synthesis is to a large extent still at a speculative state, yet some mechanisms have been hypothesized. ${ }^{[101]}$ In this review, the relevant information and potential theories of the mechanism that might be involved in the microbial synthesis of NPs are discussed.

\subsection{Ion Reduction Theory}

Enzymatic reduction of metal ions into stable NPs is thought to be one of the most commonly occurring mechanisms of the microbial biosynthesis of NPs. It has been generally found that bacteria produce an integral transmembrane nitrate reductase enzyme (NRE), which is supposedly directly involved in the reduction of metal ions to the stable nanoforms. Avazeri et al. demonstrated that NRE from E. coli could reduce selenate or tellurite to elemental form. ${ }^{[102]}$ Kalimuthu et al. reported that planktonic B. licheniformis produced NRE which was shown to reduce silver ions to metallic silver. ${ }^{[32]}$ In this case, it is probable that the electron shuttle operated by the NRE is part of the metabolism leading to the reduction of silver ions. Additionally, the activity of NRE depends on the availability of electrons through the NADH electron transport system, and hence on the bacterial respiration. The NADHdependent enzymes and the cofactor NADH were indeed secreted by $B$. licheniformis ${ }^{[103]}$ indicating that the dependence of NADH on NRE is possibly involved in the mechanism of silver ion reduction to AgNPs. Ahmad et al. suspected that F. oxpsporum synthesized four high molecular weight proteins and a NADH-dependent reductase enzyme, which reduced silver ions to AgNPs (Figure 2). ${ }^{[4]}$ Recent work by Lampis et al. suggests that the intracellular reduction of selenite is mediated through a NADH alcohol dehydrogenase homologue that is exported out of the cell. ${ }^{[104]}$

Sneha et al. reported AgNPs or AuNPs that were formed on the surface of the mycelium when they used the biomass of Verticillium sp. ${ }^{[14]}$ They proposed that the metal ions being positively charged interact electrostatically with the envelope of the fungal spores or mycelium (being negatively charged due to the carboxylate groups) allowing to trap and accumulate silver ions on the microbial cells. It is, however, still unclear, how the metal ions coordinate exactly at the microbial cell wall. As the metal ions accumulate, the reduction-inducing enzymes are synthesized concurrently by the microbial cells/mycelia. Gold or silver nuclei are then formed by enzymes reducing the silver ions, which grow further and form stable NPs. ${ }^{[14]}$

The ion reduction mechanism is also involved in the synthesis of nanomaterials from metal ions that have varying levels of toxicity to different microbes such as $\mathrm{Co}^{2+}, \mathrm{Cu}^{2+}, \mathrm{Cd}^{2+}, \mathrm{Hg}^{2+}$, $\mathrm{Ni}^{2+}, \mathrm{Pb}^{2+}$, and $\mathrm{Zn}^{2+}$. The microorganisms develop genetic and subsequent proteomic responses to tolerate the otherwise lethal concentrations of these metals by regulating the metal homeostasis. ${ }^{[105]}$ As a result, several metal resistance gene clusters have evolved, which work to detoxify the metal by the activation of mechanisms like complexation, sequestration, or reductive precipitation as well as nontransformative mechanisms of efflux to keep the intracellular concentration low. ${ }^{[106]}$ Due to induction or activation of the resistance mechanism(s), the bacteria survive in the metal ion solution, ${ }^{[107]}$ and mediate the formation of NPs from extracellular metal ions.

Besides enzymes, the noncatalytic proteins, enzymatic metabolites, and polysaccharides produced by the microorganisms are also possible reducing agents involved in the formation of NPs. Wei et al. treated the culture filtrate of B. amploliquefaciens to deactivate the enzymes present in the filtrate. ${ }^{[108]}$ The addition of this CFCF still induced the synthesis of AgNPs. They suggested that the bacterial proteins provided functional groups to induce the formation and stabilization 
of AgNPs. Similarly, the proteins synthesized by the fungus F. oxpsporum induced the formation of AgNPs and provided stability to the particles. ${ }^{[45]}$ Brayner et al. have proposed that the polysaccharides produced by cyanobacteria may bring about the formation and stabilization of NPs. ${ }^{[60]}$

From the above information, it can be concluded that proteins, including the reduction-catalyzing enzymes produced by the microorganisms significantly contribute to the reduction of metal ions to the NPs. Aldehyde-containing sugars of the cell wall act as reducing agents and may also be involved in these redox processes. Other proteins and polysaccharides as well as cell wall secretions of the microorganisms can provide stability to the NPs most probably through coating, hence surface coordination to the particles.

Shedbalkar et al., described a common mechanism that is underlying the reduction of $\mathrm{Au}(\mathrm{III})$ ions to form AuNPs. ${ }^{[109]}$ In this mechanism, secreted enzymes could be a key factor in the nucleation and growth of AuNPs from Au ions. Amino acids and proteins act as stabilization agents for the formed AuNPs. As for silver, the mechanism for the formation of AuNPs involves electrostatic interactions between the metal cation and the negatively charged cell wall, and enzymes associated with the cell surface provide electrons to the gold ions to form atomic aggregates and small NPs, which further diffuse through the cell wall to be finally found inside of the cell. ${ }^{[110]}$

From the above discussion, it can be concluded that in general, the mechanism of NP synthesis may involve three phases, viz. activation, growth and termination (Figure 2). Some researchers have named these steps as trapping and bioreduction in comparison with metal biomineralization induced by fungi, ${ }^{[42]}$ for which the metal ions are also said to interact electrostatically with the surface of fungal spores. Therefore, one may also include a previous step of biosorption and import for those systems where the subsequent steps are intracellular. Metal reduction is then accomplished by enzymes that populate the cell wall. After the reduction step, the reduced ions combine into small clusters that coalesce into nanoparticles by undergoing coarsening eventually reaching a stable shape and size of the formed nanoparticles. The particles are then further stabilized by an organic coating.

\subsection{UV Photoconversion Theory}

It was proposed by Wang et al. that $\mathrm{AgCl}$ could further react to form AgNPs by UV photoconversion mediated by DNA templates. ${ }^{[111]}$ The photosensitivity of $\mathrm{AgCl}$, like in silver photography, was apparently responsible for the rapid production of AgNPs. This effect may be exploited using visible light irradiation that may be enhanced by the specific dyes or color sensitizers. According to this theory, a photon from visible light is absorbed by AgCl crystals. As a result, an electron-hole pair is generated, followed by combination of $\mathrm{e}^{-}$and $\mathrm{Ag}^{+}$leading to the clustering of silver species in presence of peptides or proteins (see also Section 3.3.3). Key proteins like metallothioneins that have the capacity to bind silver species and scavenging superoxide and hydroxyl radicals ${ }^{[112]}$ could accelerate this photoconversion of silver ions to $\mathrm{Ag}^{0}$.

\subsection{The Mechanism at the Molecular Level}

Given that most of the literature in this field has mostly concentrated on exploring AgNPs, our examples are biased to this element. However, the mechanism of the reduction of metal ions likely resembles the AgNP formation mechanism(s) in one or more steps. It should, however, be mentioned that for silver, only a one-electron reduction is required to obtain an atom, whereas for other metal ions like palladium, platinum, or gold, typically two or three electrons are needed to form the corresponding atom. An interesting synthetic challenge with silver is that it has no biological role in the body and that the $\mathrm{Ag}^{0}$ atom is easily reoxidized, thus there is a potential rate-limiting step in obtaining the threshold amount of silver atoms to coagulate for nucleation and growth into an AgNP can take place, as explained in Section 3.3.1.

\subsubsection{Molecular Mechanism of Biomineralization}

While there are many examples of metal NP production using biotechnology, there is still a lack of understanding of this process at the molecular level. As the most is understood about the biochemical processes for silver, we will primarily use recent examples of AgNPs for illustration. The process of metal NP formation by bacteria starting from metal ions is initiated by an electron transfer process mediated by a reducing agent. At this time, there are generally three different processes known:

a) Extracellular metal ion reduction is induced by one or several components of the medium surrounding the bacteria (e.g., the growth medium or by biomolecules released from the bacteria during their metabolism). This is considered as a direct chemical reduction, similar to processes with ascorbic acid, citric acid, $\mathrm{NaH}$, or $\mathrm{NaBH}_{4}$ in the presence or absence of capping agents. Capping agents such as proteins, lipids, carbohydrates, or nucleic acids will bind to the metal ions and the surface of NPs and thus control their size and shape. This has been shown by others and will thus not be discussed in detail here further (for further reading and recent reviews see refs. [113-115]).

b) Reduction process driven by a light-induced electron transfer between biomolecules and the metal. As this is a biogenic process, it is also influenced by the presence of capping agents such as peptides/proteins. It can be differentiated between a light-induced reduction in presence or absence of chloride/halide, and we will give a short overview on this aspect in the next paragraph.

c) Direct contact with biomolecules on the surface of a living organism (e.g., cell wall, pili, flagella, membranes, proteins, enzymes, or extracellular polymeric substances). This is at first sight similar to case (a), but the biological reduction catalysts are directly associated with the cell and thus can harvest continuously electrons from the respiring cell for the reduction of the metal ions.

\subsubsection{Light-Induced Formation of AgNPs in Absence of Halides}

In this mechanism, the electrons needed for the reduction of the metal ion are provided by excited biomolecules 


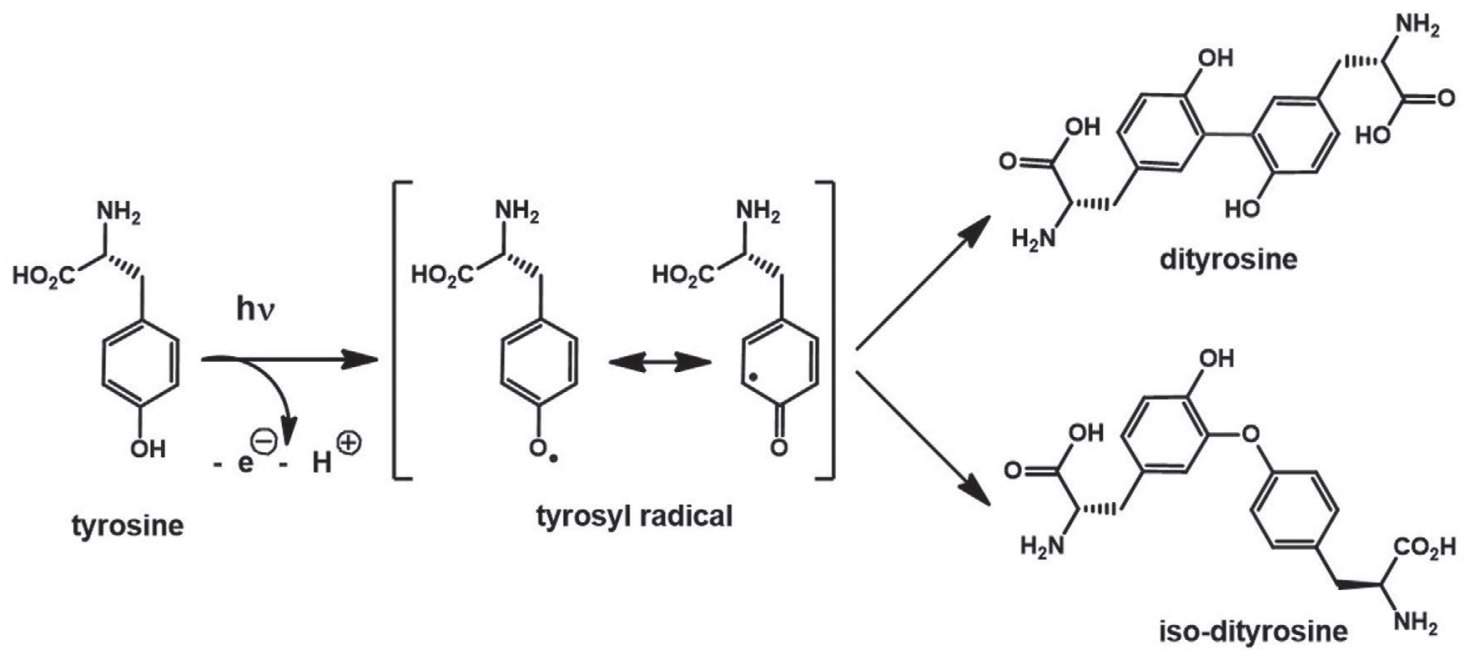

Figure 3. Electrons can be generated from aromatic amino acids through absorbance of light in the UV range. Example here is with tyrosine.

upon irradiation with light. In proteins, aromatic side chains of amino acids adsorb at wavelengths from 240 to $300 \mathrm{~nm}$. Tyrosine with its phenol side chain undergoes deprotonation in the excited state resulting in a tyrosyl radical (Figure 3 and ref. [116]). Similar excited state chemistry is possible with tryptophan, where an electron is ejected in the excited state. ${ }^{[117,118]}$ The tyrosyl radicals can then recombine to interconnect proteins via dityrosine or iso-dityrosine bridges. The leftover electron could be used to reduce a metal ion, such as $\mathrm{Ag}^{+}$. This is, for example, a possible route to AgNPs in the case of the previously mentioned fungus $F$. oxpsporum, ${ }^{[45]}$ which has a high tryptophan and tyrosine content.

For a metal ion to interact with a protein containing, e.g., tyrosine, it needs to be bound to the protein to ensure electron transfer at a reasonable rate. The single amino acids have been classified with respect to their theoretical binding constants to silver ions for a 1:1 complex formation, ${ }^{[119]}$ with free energy values that indicate arginine, lysine, histidine, and glutamine as best chelators, even before methionine and cysteine. This is surprising with respect to classical coordination chemistry where sulfur is often said to be the best binding partner for silver ions as compared to nitrogen or oxygen donors (likely based on the low solubility of $\mathrm{Ag}_{2} \mathrm{~S}$ and the hard/soft acid/base theory). ${ }^{[120]}$

Several peptide sequences among a library of tetrapeptides bound to polymer beads as solid phase were found to be able to reduce silver upon irradiation with light. ${ }^{[121]}$ Tyrosine was found in all these studied photoexcitable peptides along with histidine or serine. These results led to the assumption that the silver ion is coordinated by histidine or serine, and likely $\mathrm{NH}$ and $\mathrm{CO}$ from the peptide backbone and that the electron is then transferred from excited tyrosine to the metal ion to form AgNPs (Figure 4a).

To verify this hypothesis, follow-up studies used tetrapeptides His-X-Y-Tyr (1) and His-X-Y-Phe (2), replacing tyrosine with phenylalanine, and where $\mathrm{X}$ and $\mathrm{Y}$ are Pro and Aib, respectively, were synthesized (Figure $4 \mathrm{~b}$ and ref. [122]). NMR-titrations showed that the silver ion binds in a first step to histidine as confirmed by single-crystal X-ray diffraction. ${ }^{[123]}$ In the case of His-X-Y-Phe, no reaction occurs upon irradiation, while with Tyr instead of Phe, the solution turns yellow. The coloration suggests the formation of AgNPs, with an absorption band at around $430 \mathrm{~nm}$. However, the same absorption is observed for His-X-Y-Tyr when it is irradiated in absence of silver ions. This is due to the formation of a dimer with a dityrosine moiety as in Figure 3, which absorbs at a similar wavelength than AgNPs. This is one of the pitfalls when studying the biogenic formation of AgNPs solely with UV-vis. Indeed, the yellow solution obtained in the presence of silver ions after several minutes did not contain AgNPs. The AgNP formation only takes place over several hours if not days. This is because the formation of a single silver atom from a silver ion is an endergonic reaction $(-1.8 \mathrm{~V})$ and it takes an aggregation process of up to $\approx 10$ silver atoms combined before the growth into AgNPs becomes energetically favored $(>0 \mathrm{~V}$, Figure 5). Völkle et al. reported and discussed a nucleation size of $\mathrm{Ag}_{13}$ as critical size. ${ }^{[124]}$ Inorganic chemistry textbooks explain the influence of the metal ion ligand on the redox potential of the metal ion. Thus, in presence of a very strong silver ion binder like histidine, the reoxidation to silver ions and coordination by histidine is strongly favored in case of the His-X-Y-Tyr peptide. Hence, depending on the experimental conditions, it might be that the yellow coloration of the solution quantified by UV-vis spectroscopy is not enough to prove the formation of AgNPs. The presence of AgNPs needs to be further confirmed by electron microscopy combined with elemental mapping and ideally also electron (or X-ray) diffraction to confirm the presence and identity of the AgNPs. Unfortunately, many studies reported in the literature do not complement their work by using electron microscopy images to provide NP validation, which is now a standard requirement in the field.

Using less strong silver ion binding amino acids in place of histidine, e.g., serine, aspartate, asparagine, or lysine, leads to a faster formation of AgNPs, yet still the rate of the reaction is in the order of hours. ${ }^{[125]}$ For such short peptides, one can conclude that strong metal ion binders, which favor $\mathrm{Ag}^{+}$, inhibit the aggregation of silver atoms and stabilize the metal cations rather than metal atoms. Longer peptides, e.g., decapeptides, induce faster AgNP formation, probably because they can bind more than one silver ion and favor reduced metal-metal ion $\left(\mathrm{Ag}^{0}-\mathrm{Ag}^{+}\right)$interactions. 
a)
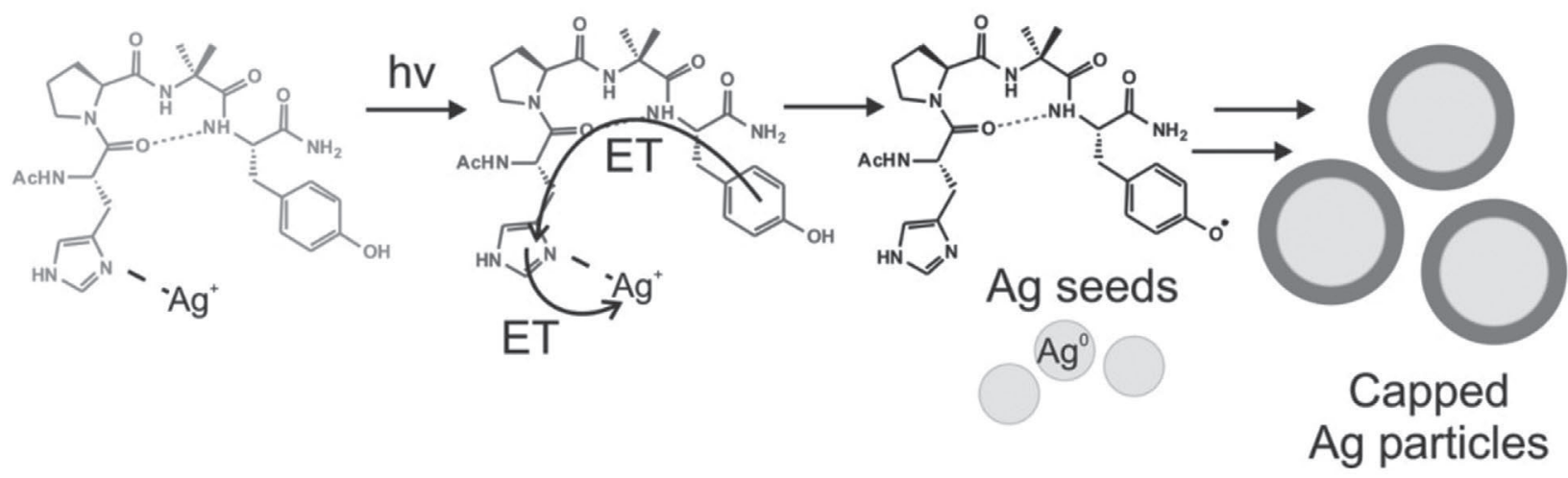

b)<smiles></smiles>

1: $X=O H, 2: X=H$

Figure 4. a) Proposed reaction mechanism for light-induced AgNP formation by first binding a metal ion to the histidine moiety of (1) and subsequent reduction by light-induced electron transfer. b) Synthesized model tetrapeptides (1) and (2) with $\mathrm{X}=\mathrm{OH}$ or $\mathrm{H}$.

The rate of the light-induced formation of AgNPs can be increased if small quantities of reducing agents such as $\mathrm{NaBH}_{4}$ are added. Then, the initially formed AgNPs, based on chemical reduction, serve as nucleation points for the further and rapid addition of atoms from the light-induced reduction. ${ }^{[122]}$ Thus, a synergic mechanism combining the chemical and the light-induced reduction of silver ions should be considered, taking into consideration the experimental conditions. Indeed, due to the variation in the composition of the growth media and buffer solutions in which the experiments are being carried out, reducing molecules may be present. Thus, comparisons between literature data are not always possible, and it is highly recommended to use as controlled conditions as possible, noting $\mathrm{pH}$, ionic strength, temperature, etc. Also, reaction rates in the absence of light should be monitored to detect possible background reactions. For instance, it is unclear in the work by Xie et al., if a light-driven mechanism is fully responsible for metal ion reduction or not as this is not properly detailed. ${ }^{[126]}$ For completeness and in contrast to tyrosine-containing peptides, tri- and tetrapeptides with the motifs His-X-Met,
His-X-Y-Met, or Met-X-Y-His can lead to light-stable silver complexes in absence of halides with $-\log K$ values ranging from 5.3 to 6.6 , depending on $\mathrm{X}$ and $\mathrm{Y}$ residues. ${ }^{[127]}$ The patterns of these sequences are found in the SilE protein that is part of a silver ion efflux pump found in silver-tolerating Gram-negative bacteria. It does not contain any tyrosine and is used as silver ion sponge and helps to transport silver ions out of the bacterial cell. ${ }^{[127]}$ In this case, many silver ions can be bound to the protein without the danger of light reduction occurring as not enough light absorbing and subsequently reducing amino acids are found in the sequence of SilE.

\subsubsection{Light-Induced Formation of AgNPs in Presence of Halides}

A different rate for the light-induced formation of AgNP is observed in the presence of chloride (or a halide in general). With halides, AgNP formation takes place within minutes. The current explanation suggests the first step is not the coordination of a single silver ion, but rather the formation of

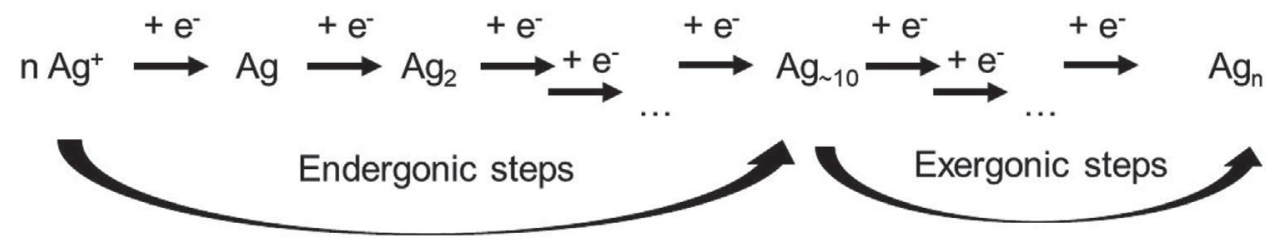

Figure 5. The first reduction steps during the formation of AgNPs from individual silver atoms are endergonic. It requires a minimum of at least ten silver atoms to drive the further reduction steps toward a spontaneous reaction. 

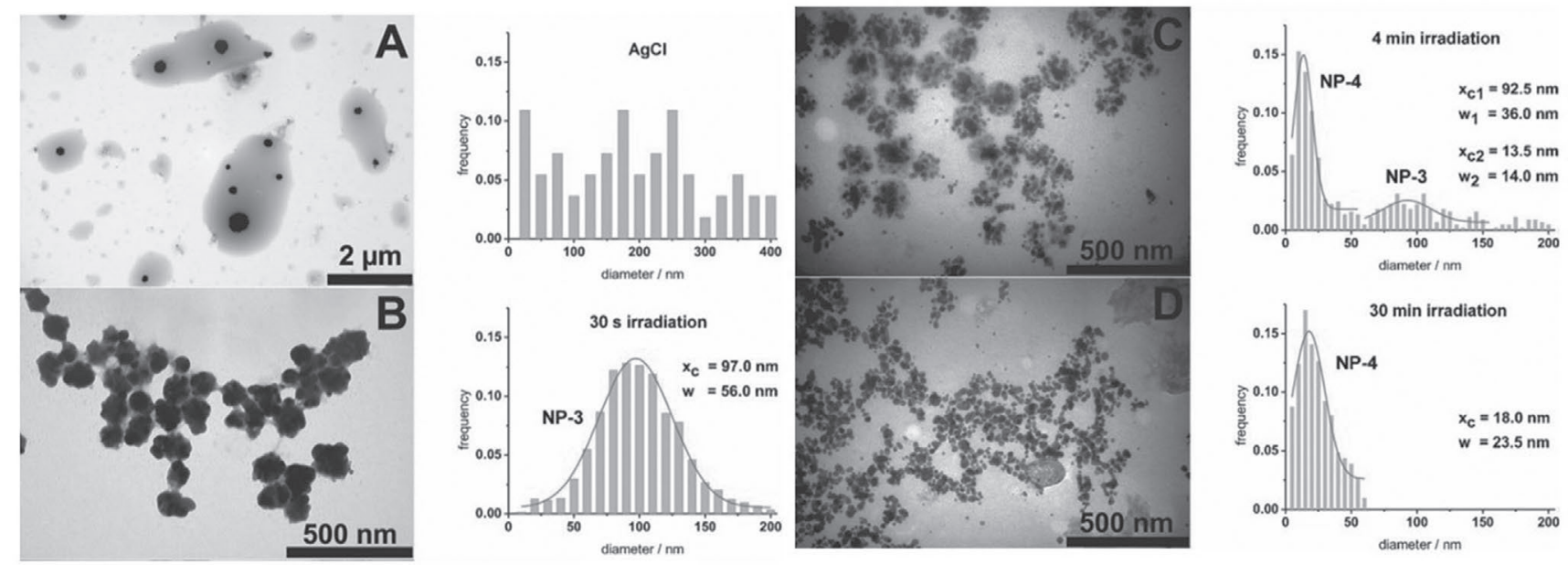

Figure 6. Time-dependent formation of AgNPs (TEM and corresponding size distribution) as a function of the irradiation time: A) initial $\mathrm{AgCl}$ particles formed with a random size distribution before irradiation; B) after $30 \mathrm{~s}$ of irradiation, the size distribution narrowed down to $100 \mathrm{~nm}$ on average and $\mathrm{AgNP}$ formation started; $\mathrm{C}$ ) after 4 min of irradiation, nanocomposites of $\mathrm{AgCl}$ and $\mathrm{AgNPs}$ are observed; $\mathrm{D}$ ) at 30 min irradiation time, all particles transformed into AgNPs of $\approx 18 \mathrm{~nm}$ diameter. Reproduced with permission. [122] Copyright 2015, Wiley-VCH.

AgX-crystal colloids, which preaggregate the silver ions into a simple salt lattice. Upon irradiation, silver ions get reduced via the light-induced radical mechanism described in Section 3.2, and they rapidly find other silver atoms in close proximity for further aggregation into clusters and AgNPs. The intermediate steps still depend on the presence of proteins or peptides with aromatic amino acids.

For example, in presence of the model tetrapeptide 1, the formation of $\mathrm{AgCl}$ crystals with a random size distribution of particles between $\approx 20$ and $400 \mathrm{~nm}$ before irradiation is observed. ${ }^{[122]}$ After $30 \mathrm{~s}$ of irradiation, the size distribution narrowed to $\approx 100 \pm 50 \mathrm{~nm}$ and first AgNPs were detected (Figure 6). After 4 min of irradiation, two types of NPs were observed: AgNPs of around $15 \mathrm{~nm}$ and $\mathrm{AgCl} \mathrm{NPs} \mathrm{of} \approx 100 \mathrm{~nm}$, and the TEM showed the formation of a nanocomposite of the two compounds. At $30 \mathrm{~min}$ of irradiation,

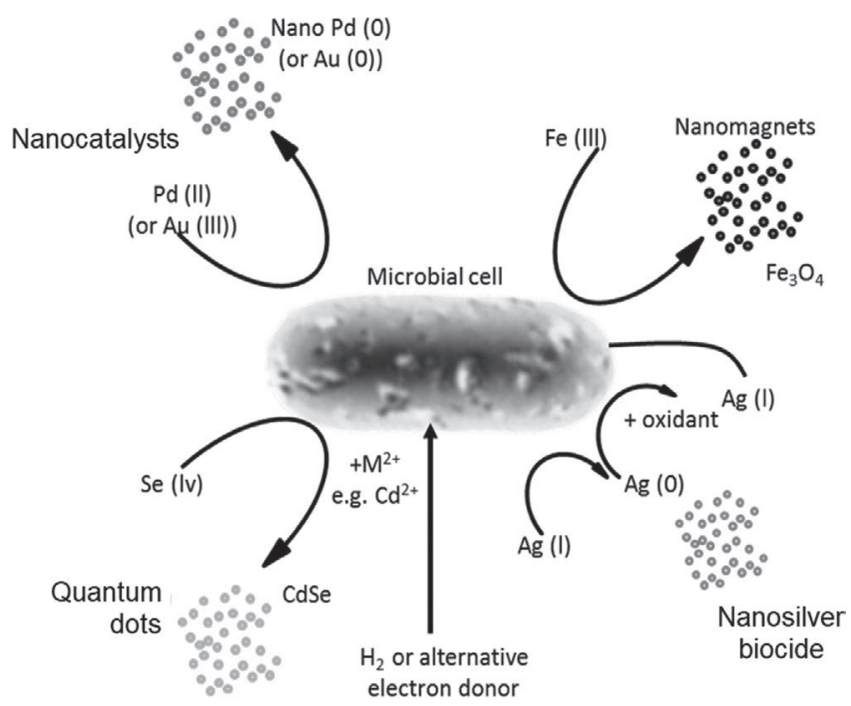

Figure 7. Schematic examples of NPs biomineralization using bacteria. Reproduced with permission. ${ }^{[129]}$ Copyright 2011, Elsevier. only small AgNPs of $\approx 20 \mathrm{~nm}$ remained in the sample. This is a case where NPs get smaller upon irradiation, due to the decomposition of $\mathrm{AgCl}$ into AgNPs. Using less effective silver ion binding amino acids instead of histidine, such as serine, aspartate, asparagine, or lysine, the intermediate nanocomposites are not observed, but one directly observes formation of AgNPs, indicating a faster nucleation and growth. ${ }^{[125]}$ This again shows the potential of histidine to stabilize rather $\mathrm{Ag}^{+}$than $\mathrm{Ag}^{0}$.

In some cases, no AgNPs are produced but solely AgCl NPs. This was observed in the case of microalgae Chlorella vulgaris, plant extracts, and bacteria. ${ }^{[128]}$ In the case of the microalgae, a color change during the formation of $\mathrm{AgCl} \mathrm{NPs} \mathrm{of} \mathrm{the} \mathrm{medium}$ was observed in the dark, and only $\mathrm{AgCl}$ NPs were identified. Hence, the presence or absence of chloride (in general halide) is crucial during the irradiation-induced formation of AgNPs. Since chloride can hardly be avoided when living organisms are being used, this mechanism may be a contributor in all cases where there is no control of the chloride concentration nor the light.

\subsubsection{Electron Transfer through Proteins and DNA}

It has been reported that bacteria can form NPs of minerals, using electron transfer processes (Figure 7). ${ }^{[129]}$ Therefore, it is likely that biomolecules such as sugars, proteins, or DNA are involved in this mechanism, as explained in more detail next. The process involving reducing sugars (aldehydes) has been described for several examples ${ }^{[130,131]}$ and the classical Tollens reagent is well known in this context, using an aldehyde to reduce silver ions.

In nature, electron transfer can take place via super exchange mechanisms, typically over shorter distances than 10-15 $\AA$, or via a hopping process, typically using biomolecule stepping stones, to cover long distance electron transfer. ${ }^{[132]}$ One example is described for ribonucleotide reductase, ${ }^{[133]}$ in which cysteine residues of the active site donate electrons to a diferric 


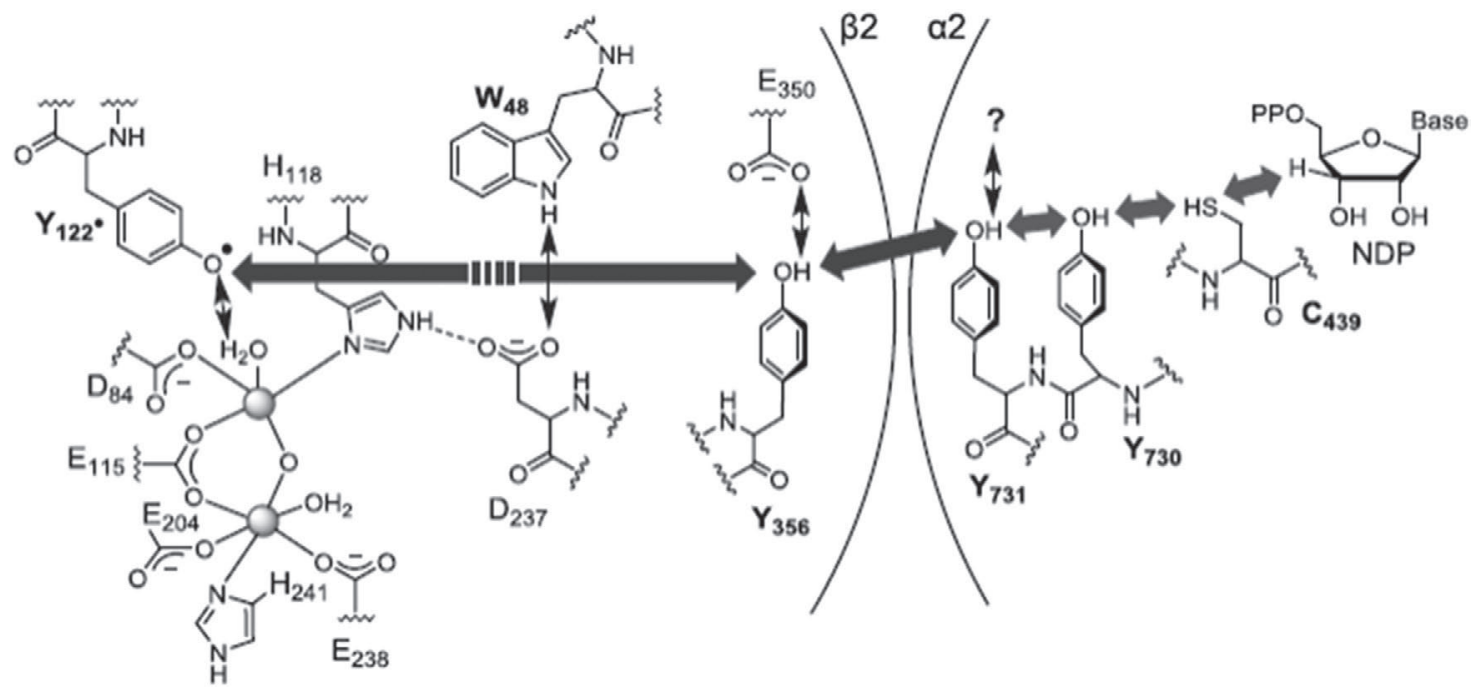

Figure 8. Proton-coupled electron transfer mechanism for long-range electron transfer in E. coli ribonucleotide reductase. Reproduced with permission. ${ }^{[134]}$ Copyright 2013, American Chemical Society.

oxo-bridged entity that is $35 \AA$ away from the active site. A tyrosine close to the diferric cluster is oxidized chemically (not with light) in a proton-coupled electron transfer (PTEC) process (electron transfer and loss of proton occur at the same time) (Figure 8). The tyrosyl radical can then react with a nearby glutamate in a protein that is oxidized to glutamic acid, again in a reversible proton-coupled reaction. Such a proton-coupled electron transfer takes place via several amino acid side groups in the protein that can act as stepping stones, in particular tyrosine, histidine, tryptophan, as well as cysteine.

The time-resolved chemical mechanism has been studied in detail using nanosecond laser spectroscopy on model peptides (Figure 9) in which a ground state radical cation (electron hole) can be generated with a laser flash, inducing electron transfer. It was shown that the speed and direction of electron (respectively hole) transfer can be influenced by the sequence of the amino acids, hence their relative redox potentials, their structure, hence their dipole moment, as well as by their relative distribution of charges. ${ }^{[135]}$ In addition to the amino acids identified in the ribonucleotide reductase, they found cysteine and methionine as possible relay stations for electron transfer processes in proteins, although the redox potential for methionine is not favorable. ${ }^{[136]}$ Nevertheless, electron transfer can take

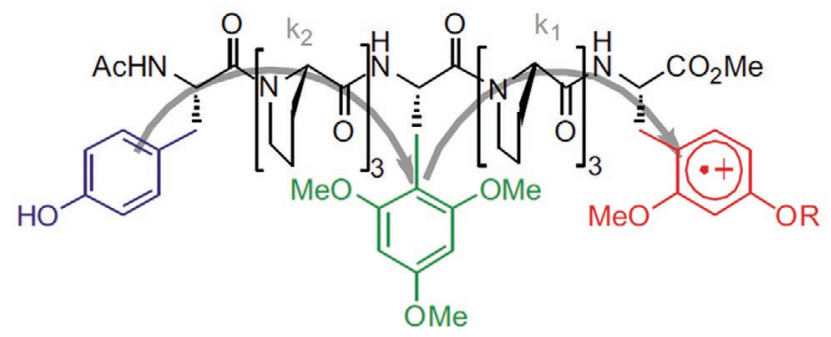

$$
\mathrm{k}_{2}=3.0^{*} 10^{7} \mathrm{M}^{-1} \mathrm{~s}^{-1} \quad \mathrm{k}_{1}=3.3^{*} 10^{6} \mathrm{M}^{-1} \mathrm{~s}^{-1}
$$

Figure 9. Model peptide to study the kinetics of electron transfer through proteins. place using methionine if a neighbor oxygen atom of an amide group can act as stabilizing agent in the delocalization of the radical (Figure 10). Neighbor group effects may also be responsible for other amino acids being active in electron transport, yet to be confirmed. The case of phenylalanine, also stabilized by a neighbor group effect, is discussed further in Section 3.3.5.

These experiments are important puzzle pieces to understand the metal ion reduction, as similar to the positive charge generated in these model peptides, the silver ion with its positive charge can also act as thermodynamic "sink" to which electrons flow through the protein to generate elemental silver atoms leading to AgNPs. Such electron transfer processes have also been studied in a similar way for the other important biopolymers, namely DNA and RNA, for which also a hopping mechanism was found for long distance electron transfer. ${ }^{[137]}$ Indeed, the bases $\mathrm{G}$ and A can act as relay stations in the DNA for the transport of holes, while $\mathrm{C}$ and $\mathrm{T}$ are used for excess electron transfer ${ }^{[138]}$ and this process should possibly be kept in mind and studied in more detail for the examples mentioned in this review in which DNA is discussed as playing a crucial role in or during the metal ion reduction or coordination. ${ }^{[139-141]}$

\subsubsection{Metal Ion Reduction in Contact with Living Bacteria}

Both aerobic as well as anaerobic microbes can reduce metal ions, and, in both cases, intracellular and extracellular<smiles>CC(=O)N[C@H]1CC[S+](C)OC1</smiles><smiles>CSC1CC2CC(C)C1C2C(N)=O</smiles>

Figure 10. A neighbor group effect can help methionine to act as a charge transfer agent in a protein chain. Reproduced with permission. ${ }^{[136]}$ Copyright 2012, Swiss Chemical Society. 


\section{$\mathrm{ET}$ by $\mathrm{Fe}^{2+} / \mathrm{Hemes}$ of $\mathrm{c}-\mathrm{Cyt}$}

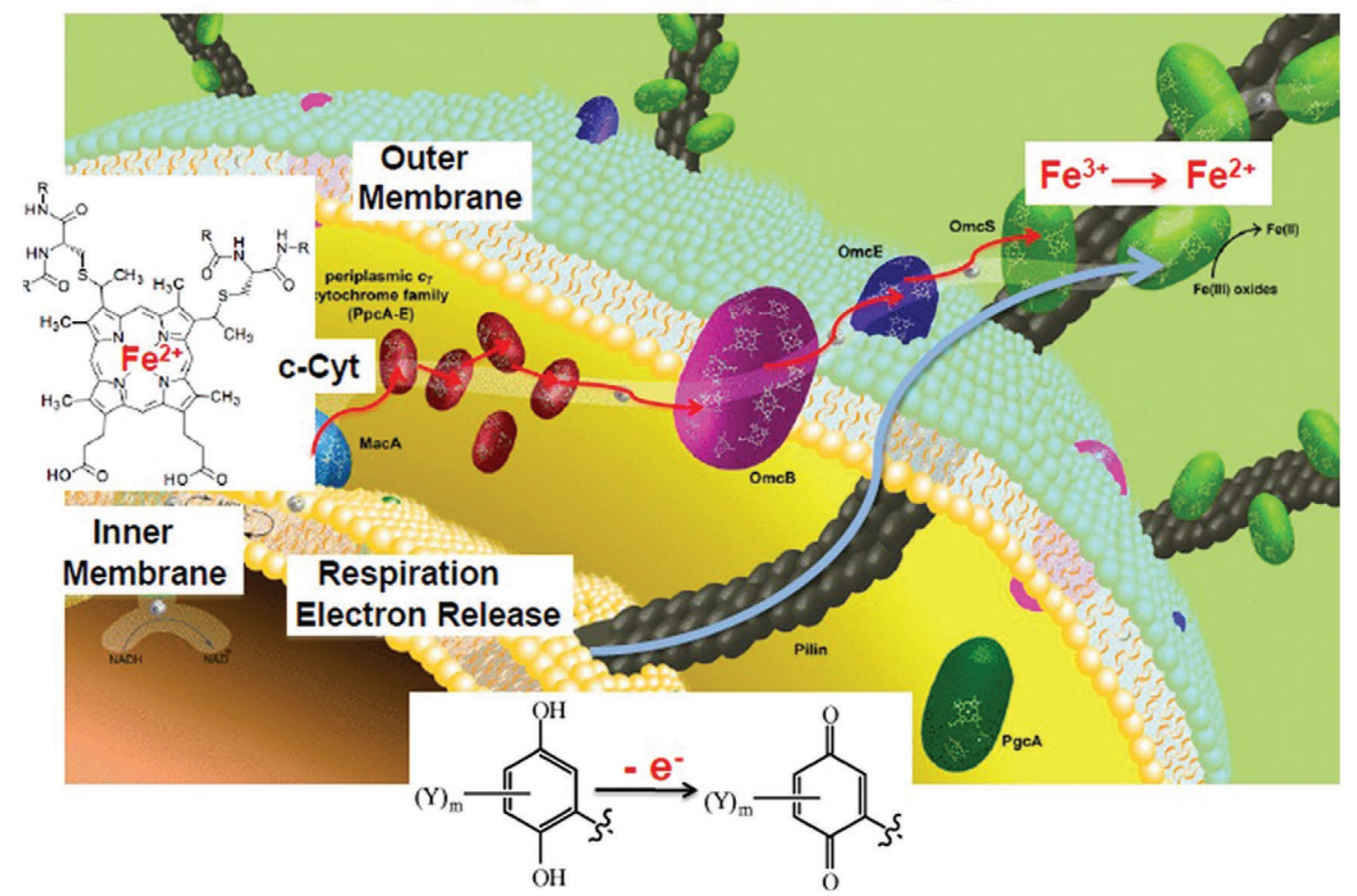

Figure 11. Possible electron transfer processes to the outer cell membrane of Gram-negative bacteria. Cytochrome-mediated transfer via periplasmic to outer membrane cytochromes (red arrows), or via proteins assembled into pili (blue arrow). Adapted with permission. ${ }^{[143]}$ Copyright 2012, Portland Press.

reduction processes are observed. Intracellular reduction has been observed for AuNPs produced in B. subtilis, ${ }^{[142]}$ and this might be due to the fact that the gold source most frequently used is $\mathrm{AuCl}_{4}^{-}$, an anionic species for which there might be transporters in the cell membrane that permit this ion to cross the cell membrane similar to phosphate, sulfate, or nitrate. The negative charge and low charge density of $\mathrm{AuCl}_{4}^{-}$may also favor a passive membrane diffusion. Overall, reduction at the outer membrane has been more frequently reported to date. There are several options on how metal ions can get reduced near or at the membrane: lipopolysaccharides may reduce metal ions if they contain reducing sugars, as mentioned above. In direct contact with the membrane, next to the previously mentioned NRE, outer membrane cytochromes have been discussed as places where the reduction can take place, and finally metal ion reduction was also observed at the pili of bacteria, suggesting that the latter can act as nanowires (Figure 11). ${ }^{[143]}$

Among the bacteria able to reduce metal ions at the outer cell membrane, S. oneidensis and G. sulfurreducens (dissimilatory metal-reducing bacteria) have been studied in the most detail. ${ }^{[144]}$ Bacteria like Geobacter and Shewanella typically express a large variety of c-type cytochromes contained in the cell envelope and are considered to transport electrons from the inner membrane, taking their electrons from the quinone pool, to the outside. Several different types of c-type cytochromes are at play: Some can act as electron carriers in the outer membrane with, e.g., 12 heme units, while others are smaller, e.g., with three heme units, acting as electron shuttles in the periplasm. Yet, the exact interplay between them ${ }^{[145]}$ and electron flow within each cytochrome ${ }^{[146]}$ is still under investigation. It has also been reported that small monoheme c-type cytochromes are excreted by G. sulfurreducens and might participate in the bioreduction of $\mathrm{Fe}^{3+}$ or transfer electrons to partner bacteria. ${ }^{[147]}$ Recent measurements confirm the presence of cytochromes in the extracellular polymeric substances (EPS) and report an electron transfer rate of $0.026 \mathrm{~s}^{-1}$ for the microbial extracellular electron transfer that influences redox reactions of intact Shewanella cells. ${ }^{[148]}$ For Geobacter, the octaheme outer membrane c-type cytochrome OmcZ was isolated extracellularly and shown to contribute to the electron transfer process to $\mathrm{Fe}^{3+}$ and other soluble metal ions in higher oxidation states like $\mathrm{U}^{6+}, \mathrm{Cr}^{6+}, \mathrm{Au}^{3+}$, and $\mathrm{Mn}^{4+}$. ${ }^{149]}$ Similar reduction tests with sterilized culture supernatants of Geobacter did however not yield AgNPs, while silver ions are reduced in contact with living bacteria. ${ }^{[33]}$ This study also showed that if two cytochromes, namely the inner membrane bound periplasmic MacA and the outer membrane $\mathrm{OmcF}$, are lacking; electron transfer to silver is slowed down. AgNP production is, however, never completely suppressed, indicating that other cytochromes are also involved in the electron transfer process, which was measured by monitoring the silver ion concentration in the supernatant over time and occurs at a rate of $7.26 \mu \mathrm{mol}$ of $\mathrm{Ag}^{+}$per milligram of protein dry weight per hour and $K_{\mathrm{m}}$ being roughly $90 \times 10^{-6} \mathrm{M}$. A direct proof for the participation of cytochromes in the silver ion reduction and formation of AgNPs in living bacteria was 

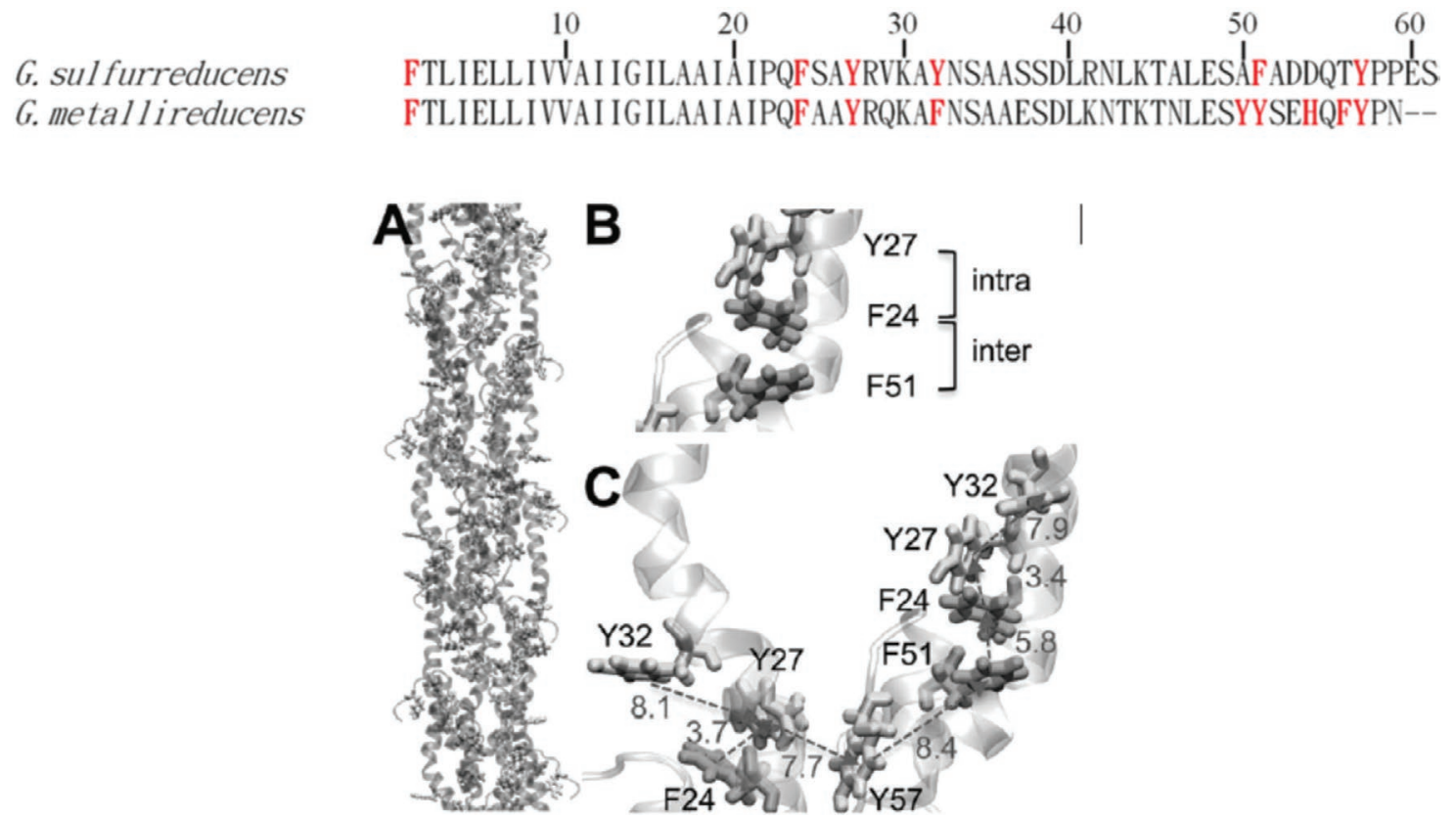

Figure 12. Top: Amino acid sequence comparison of the proteins forming the pili in G. sulfurreducens compared to G. metallireducens; Reproduced under the terms and conditions of the Creative Commons CC-BY License. ${ }^{[151]}$ Copyright 2017, American Society for Microbiology. Bottom: $A, B)$ Packing of proteins into pili; C) Examples of intra- and intermolecular interactions of aromatic side groups of amino acids tyrosine (Y) and phenylalanine (F) moieties in pili. Reproduced with permission. ${ }^{[150]}$ Copyright 2015, Royal Society of Chemistry.

given by following the relative amounts of $\mathrm{Fe}^{2+}$ and $\mathrm{Fe}^{3+}$ hemes and the increase of the AgNP concentration by UV-vis spectroscopy ${ }^{[125]}$ While horse heart c-cytochrome alone, similar to the supernatant of G. sulfurreducens, is unable to reduce the silver ions due to the endergonic first reduction steps to elemental silver (see Figure 5), bacteria continuously produce electrons during their mineral respiration process, and possess thus enough "driving force" for the generation of AgNPs. This emphasizes that the availability of excess silver ions and electrons (i.e., supplied from the metabolism) are requirements to ensure the nucleation and growth of silver clusters for a successful AgNP synthesis. On a single protein level, further research is needed to clarify whether a single multiheme c-type cytochrome would provide enough electrons to form a stable silver nanocluster.

A second pathway for making AgNPs involves the pili of the bacteria. Pili are the long filaments made of assembled pilin protomer units that each contain $\approx 60$ amino acids, including the key residues histidine, tyrosine, and phenylalanine (Figure 12). ${ }^{[150]}$ They coil into a helical structure and interact with each other to build up the pili. Intermolecular interactions between oppositely charged amino acids and among aromatic groups are responsible for their aggregation and the electron transfer via a hopping mechanism. ${ }^{[151]}$ The pilus of G. metallireducens versus $G$. sulfurreducens shows increased conductivity by the pili, and is likely based on an increased amount of tyrosine, histidine, and phenylalanine near the $\mathrm{C}$-terminus. The participation of phenylalanine is at first sight surprising, as its oxidation potential is higher than that for tyrosine, for example, yet, it could be shown to participate in electron transfer processes due to a neighboring group effect, which occurs in proteins. ${ }^{[152]}$ The recent discovery using cryo-electron microscopy showed that some pili from conductive G. sulfurreducens contain in the center of the filament a chain of head-to-tail stacked outer membrane OmcS, leading to a nanowire that is apparently also involved in long-range electron transfer. ${ }^{[153]}$

The third pathway through which bacteria may form AgNPs is via contact with extracellular polymeric substances as a source of aldehyde functional groups. EPS from S. oneidensis, P. putida, and A. hydrophila were isolated and exposed to $1 \times 10^{-3} \mathrm{M}$ silver nitrate, which led to AgNP formation. ${ }^{[154]}$ The formation process was slow (up to $18 \mathrm{~d}$ ) compared to living bacteria (several minutes to hours). Matrix analysis indicated that c-type cytochromes and not the sugar units of the polysaccharides may be the responsible for the synthesis of AgNPs in this case. All EPS-produced AgNPs had a similar shape and size of 5-35 $\mathrm{nm}$ and the $S$. oneidensis produced AgNPs with highest crystallinity among the tested species. ${ }^{[154]}$

Overall, the process of metal nanoparticle formation is highly complex, and the field and understanding are still quite young. Careful focused investigations at the molecular level are required to properly understand the biomineralization processes and molecular intermediates involved in the formation of metal NPs. ${ }^{[155]}$

\section{Microbial Synthesis of Metal Nanoparticles in Biofilms}

Biofilms are formed by microorganisms attached to surface and encased in a self-produced extracellular polymeric matrix, which confer mechanical stability to this microstructured community (Figure 13). Biofilms offer an ideal environment for numerous catalytic processes due to the proximity of the microorganism, which decrease diffusional limitations, and the high 


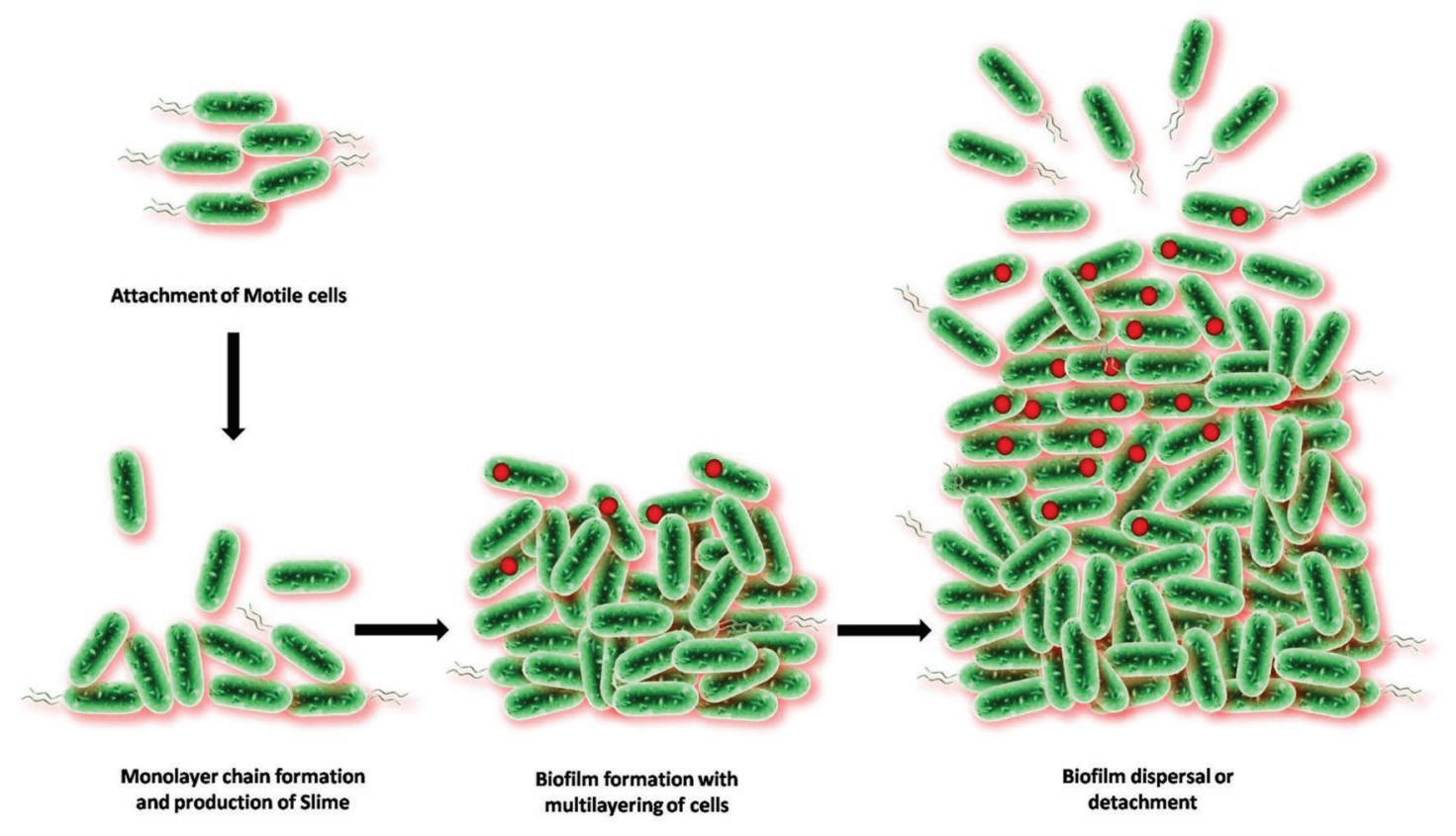

Figure 13. Life cycle of a typical baterial biofilm.

concentration of active microorganisms, which result in a high reaction rate. Plus, biofilm immobilization allows retaining the catalyst at the end of the biosynthetic process, thus facilitating the recycling and scale-up. ${ }^{[156]}$

These favorable characteristics have been explored to carry out microbial biosynthesis of metal nanoparticles. Metal bioreduction and consequent formation of nanoparticles is a well-known detoxification mechanism for dissimilatory metal-reducing microorganisms. Although the appearance of nanoaggregates of metals has been observed in early biogeochemical studies, ${ }^{[157,158]}$ they have not been specifically identified or termed nanoparticles and in most studies, NP biosynthesis was not proposed as an alternative to physicochemical synthetic methods.

Outside the metal-reducing bacteria, metal ions ${ }^{[120]}$ and metal nanoparticles are well-known to have a strong inhibitory effect on planktonic cells and biofilms, ${ }^{[159]}$ although the formation of biofilms and aggregates contributes to reduced metal and nanoparticle toxicity with respect to their planktonic counterpart. ${ }^{[160]}$

A recent review focuses on this issue. ${ }^{[161]}$ However, few studies have been published since then. Considering that metal bioreduction and the consequent formation of metal nanoparticles is a detoxification strategy for microorganisms, it is likely that NP biosynthesis in biofilms can be achieved only for metaltolerant strains or for biofilms where the extracellular matrix decreases NP toxicity, thus particular care should be used in designing NP biosynthesis studies in biofilms.

An anaerobic sludge consortium biofilm was used to synthesize small polycrystalline AgNPs $(1-7 \mathrm{~nm})$ from $\mathrm{AgNO}_{3}$ with sodium acetate as energy source. ${ }^{[162]}$ The biofilm was formed by adhesion to carbon paper. Aggregates of AgNPs were rapidly synthesized in the extracellular space. In minimal medium, the bioreduction was likely due to the lack of oxygen and other extracellular electron acceptors, which results in rapid formation of small AgNPs. Neither the toxicity of biosynthetic AgNPs on the anaerobic biofilm nor the long-term sustainability of this bioreduction strategy was investigated. This is one of the few studies that does not employ dissimilatory metal-reducing bacteria. It is likely that lactobacilli involved based on the electron donor supplied in anaerobic sludge contribute to the bioreduction. As it is not uncommon to observe metal resistance in sewage microbial communities, ${ }^{[163]}$ the use of such inoculants could be considered.

A recent study on metal-tolerant lactobacillus, Enterococcus faecalis, has shown the formation of reduced iron nanoaggregates, both intracellularly and extracellularly in the biofilm matrix, as revealed by TEM imaging. ${ }^{164]}$ This bioreduction process was defined to occur by extracellular electron transfer through the membrane-associated quinone dimethyl menaquinone [DMQ]. The extracellular biosynthesis of selenium nanoparticles has also been published for this strain, although no TEM images of the extracellular material were reported.[165] Enterococci are known for their tolerance to multiple toxic metals, ${ }^{[166,167]}$ which play a role in their nanoparticle biosynthesis capability.

While the properties of bacterial biofilms are well-defined and consistently reported in the literature, there is less agreement on the definition of fungal biofilms. However, biofilms of Candida sp. ${ }^{[168]}$ and Fusarium sp. have been extensively investigated in implant-related infections. ${ }^{[169]}$ Evaluation of pellicle biofilms of Candida sp. showed morphological changes upon exposure to multiple metals ${ }^{[170]}$ and differences in individual cells versus mycelium, ${ }^{[171]}$ but unfortunately these studies did not evaluate if nanomaterials were produced. In other microorganisms, such as Aspergillus sp. and Pneumocystis sp., single cells appear embedded in the extracellular matrix, which is part of the biofilm phenotype, but lacks the other biofilm properties. 
Algal biofilms are relevant to ecosystem biogeochemistry in both freshwater and seawater. ${ }^{[172]}$ Algal biofilms concentrate nanoparticles in their extracellular matrix, thus are relevant to the environmental fate of metal nanoparticles. ${ }^{[173]}$ Extracellular biosynthesis of AuNPs in diatoms biofilms has been reported as a metal detoxification mechanism. ${ }^{[174]}$ Similar observations were reported for two other diatom biofilms, Navicula atomus and Diadesmis gallica, where AuNPs were formed in the extracellular polymeric substance. ${ }^{[175]}$

While most studies were performed in cell suspension, a small number of studies reported extracellular biosynthesis of NPs, where the EPS play a major role in the formation and immobilization of the NPs. The mechanism appears like those for biosynthesis in cell suspension and is explained with metal detoxification of the environment surrounding the cells. This is in agreement with the general observation that planktonic and biofilm cultures tend to have similar susceptibility to most metals. ${ }^{[176]}$ This is in contrast to organic antibiotics that typically have less efficacy against biofilms. ${ }^{[177]}$ It is assumed that the extracellular matrix would concentrate NPs to high levels and thus biofilms could be used for the scale-up of NP production in industrial applications. This could however lead to larger sized crystal formation as obtained for silver or copper microcrystals observed in mixed community biofilms under high metal load. ${ }^{[178]}$

\section{Antimicrobial Efficacy of Nanoparticles}

\subsection{Antimicrobial Efficacy of Nanoparticles on Bacteria}

A wide range of bacterial species have been found sensitive to NPs (Table 2). However, effects of NPs have been largely tested on the bacteria that are pathogenic for humans. ${ }^{[179]}$ Therefore, we have a poor appreciation of the full microbial ecological consequences. These studies were generally done using some form of an antibiotic sensitivity test method, typically, the zone of inhibition of the bacterial colonization is measured or the ability to continue to grow on plate or in liquid culture (minimum inhibitory concentration). Effects of NPs, in general, have been found to depend on the NP concentration, ${ }^{[180]}$ physiology, and metabolism ${ }^{[181]}$ of the given species, as well as the selective permeability of intracellular membranes and the kind of bacterial cell. ${ }^{[182]}$ A comparative study of silver salts to different silver oxide NPs showed that the silver formulations led to varied efficacies toward planktonic- and biofilm-grown cultures. ${ }^{[183]}$ AgNPs suppressed the colonization of E. coli, K. pneumoniae, ${ }^{[184]}$ Staphylococcus aureus, ${ }^{[185]}$ and P. aeruginosa. ${ }^{[46]}$ Among these four bacteria, the highest antimicrobial activity of AgNPs was found against E. coli and S. aureus, although one should be careful with comparing studies using different strains and growth conditions. There are several other findings on the suppressive effect of microbially synthesized metallic nanoparticles on pathogenic microorganisms. ${ }^{[186]}$ The biogenic AgNPs obtained from Brevibacterium frigoritolerans DC2, ${ }^{[8]}$ Bhargavaea indica DC1, ${ }^{[187]}$ and Sporosarcina koreensis DC4 ${ }^{[188]}$ caused antimicrobial effect against B. anthracis, B. cereus, C. albicans, E. coli, Salmonella enterica, and Vibrio parahaemolyticus. Similarly, the CuNPs synthesized by Sida acuta suppressed the colonization of E. coli, Proteus vulgaris, and S. aureus. ${ }^{[89]}$ It was further reported that when the biogenic nanoparticles were applied along with common synthetic antibiotics novobiocin, penicillin $G$, rifampicin etc., the antimicrobial activity was synergized. The zinc oxide NPs also proved suppressive to P. aeruginosa, E. coli, and S. aureus. ${ }^{[190]}$

A hybrid material, polyvinyl pyrrolidone with AgNPs (AgNPs/PVP) suppressed the colonization of $P$. aeruginosa, B. subtilis, E. coli, and S. aureus. ${ }^{[191]}$ The antimicrobial activity of AgNPs (20 mm zone of inhibition) against E. coli, S. aureus, $K$. pneumoniae, and $P$. aeruginosa performed by the well-diffusion method revealed the highest inhibition zone of $30 \mathrm{~mm}$ on the former two microbes. ${ }^{[184]}$ The AgNPs were found more suppressive to Gram-positive (2.8 $\mathrm{mm}$ zone of inhibition) than Gram-negative bacteria $(2.0 \mathrm{~mm}) .{ }^{[192]}$ Interestingly, macrophages are not affected at $100 \times 10^{-6} \mathrm{M}$ concentrations that are usually lethal to bacteria. ${ }^{[193,194]}$ Further, S. typhi and $P$. aeruginosa (Gram-negative) were also found to be more sensitive to AgNPs (4-9 mm zone of inhibition) ${ }^{[195,196]}$ than B. subtilis and Micrococcus luteus (Gram-positive, 10-11 mm inhibition zone). The greater sensitivity was attributed to the structural difference in the cell wall of these two bacteria groups. The AgNP size and type of bacterial species are further parameters influencing the antimicrobial activity. ${ }^{[197]}$ For example, AgNPs showed maximal antimicrobial activity against $S$. aureus $(19.0 \mathrm{~mm}$ zone of inhibition), followed by B. subtilis (17.0 $\mathrm{mm}), P$. aeruginosa $(14.0 \mathrm{~mm})$, and E. coli $(12.0 \mathrm{~mm}) \cdot{ }^{[196]}$ Salem et al. found antibacterial activity of ZnO NPs and silver ions against $V$. cholerae and enterotoxic E. coli. ${ }^{[198]}$ Hungund et al. reported that biosynthesized spherical AgNPs of 45-50 nm were highly effective against E. coli, $S$. typhimurium, K. pneumoniae, and $S$. aureus using the agar well-diffusion method. ${ }^{[199]}$ The largest zones of inhibition were observed for E. coli (8 mm), S. typhi (6 mm), K. pneumoniae $(8 \mathrm{~mm})$, and $S$. aureus (5 $\mathrm{mm})$, respectively. The above Grampositive bacteria inhibition zone of $5-6 \mathrm{~mm}$ seems to be less sensitive than Gram-negative bacteria inhibition zone of $8 \mathrm{~mm}$ to the same AgNPs. ${ }^{[200]}$

Spherical ZnO NPs of $57.7 \mathrm{~nm}$ have been found suppressive to $P$. aeruginosa and caused a maximum inhibition zone of $22 \pm 1.8 \mathrm{~nm}$ with $25 \mathrm{ng} \mathrm{mL}{ }^{-1} \mathrm{ZnO}$ NPs. ${ }^{[65]}$ Tangwatcharin et al. used the Gram-negative model organism Campylobacter jejuni to examine the antimicrobial effects of $\mathrm{ZnO}$ NPs on bacteria. ${ }^{[201]}$ The cells of these bacteria are spiral and motile, and highly sensitive to different environmental stresses. In response to a stress, $C$. jejuni undergoes morphological modification producing coccoid cells instead of spiral-shaped ones as was observed with the ZnO NPs. ${ }^{[202]}$ Antibacterial activity of ZnO NPs has also been observed against S. aureus, E. coli, $P$. aeruginosa, $P$. mirabilis, and $B$. cereus with $25,29,32,30$, and $30 \mathrm{~mm}$ zone of inhibition, respectively. ${ }^{[203,204]}$

The CuNPs have been found to suppress to colonization of Gram-positive and Gram-negative bacteria, ${ }^{[205]}$ in particular by $S$. aureus, B. subtilis (Gram-positive), P. aeruginosa, and E. coli (Gram-negative). In another study, biologically synthesized CuNPs greatly suppressed the colonization of E. coli and S. aureus causing 1.1 and $1.7 \mathrm{~mm}$ inhibition zones, respectively. ${ }^{[28]}$

For NPs combined with antibiotics, the antimicrobial effects were found to be increased considerably. ${ }^{[206]}$ Gandhi and Khan reported enhanced antimicrobial activity of AgNPs in the 
presence of bacitracin against E. coli and S. paratyphi (control $0 \mathrm{~mm}$, test 22 and $18 \mathrm{~mm}$ inhibition zone, respectively), ampicillin against Corynebacterium diphtheria (control $0 \mathrm{~mm}$, test $14 \mathrm{~mm}$ ), kanamycin against K. pneumoniae (control $19 \mathrm{~mm}$, test $30 \mathrm{~mm}$ ), for gentamycin against $P$. aeruginosa (control $18 \mathrm{~mm}$, test $34 \mathrm{~mm}$ ), and bacitracin, gentamycin, erythromycin, and ciprofloxacin against $S$. aureus (control 0, 14, 19, and $21 \mathrm{~mm}$, test $12,29,32$, and $30 \mathrm{~mm}$, respectively). ${ }^{[38]}$ Singh et al. found an antimicrobial activity of biosynthesized AgNPs against B. anthracis, B. cereus, E. coli, C. albicans, V. parahaemolyticus, and S. enterica. ${ }^{[207]}$

Shaikh et al. presented the mechanism involved in the antimicrobial action of cefaclor conjugated AuNPs. ${ }^{[208]}$ They reported that the antibactericidal effects resulted due to synergism between cefaclor and AuNPs. The cefaclor enhanced membrane porosity by interacting with the outer peptidoglycan layer, whereas AuNPs created holes in cell walls. As a result, the cefaclor-capped AuNPs efficiently penetrated the bacterial membranes and interacted with the DNA. The penetrated AuNPs hindered DNA unwinding and transcription. ${ }^{[209,210]}$ The conjugated treatment also led to inflow and buildup of high concentrations of cefaclor in the bacterial cells. ${ }^{[210]}$

\subsection{Effect of Nanoparticles on Fungi}

Less information is available on the effects of NPs on fungi. However, fungi have also been found sensitive to NPs. ${ }^{[211,212]}$ Mostly, the researches have used silver or ZnO NPs, and the effects are largely tested against soil-borne plant pathogenic fungi. ${ }^{[5]}$ The AgNPs were found to be suppressive to plant pathogenic fungi, F. oxysporum (MTCC 8608) and Sclerotinia sclerotiorum (MTCC 8785). ${ }^{[213]}$ Chauhan et al. reported an inhibitory effect of biosynthesized AgNPs on the colonization of A. tereus strain JAS1 (17 mm inhibition), Scedosporium sp. JAS1 (17 mm), C. tropicalis (14), and Fusarium sp. $(15 \mathrm{~mm}) .^{[9]}$ The AgNPs at $15 \mathrm{mg} \mathrm{L}^{-1}$ concentration suppressed the colonization of plant pathogenic fungi, Alternaria alternate and Curvularia lunata. ${ }^{[214]}$ The colonization of root rot and mold causing fungi, viz., S. sclerotiorum, Macrophomina phaseolina, Rhizoctonia solani, and Botrytis cinereal was inhibited due to AgNPs. Besides plant pathogens, some yeasts, C. albicans, C. krusei, C. tropicalis, C. glabrata, and a mold, A. brasiliensis have also been reported to be AgNPs/PVP. ${ }^{[191]}$

Phanjom and Ahmed synthesized AgNPs at 1 and $10 \times 10^{-3} \mathrm{M}$ concentrations by using the fungus biomass (A. oryzae). ${ }^{[215]} \mathrm{A}$ relationship between the $\mathrm{AgNO}_{3}$ concentration and particle size was also recorded. The $\mathrm{AgNO}_{3}$ up to $8 \times 10^{-3}$ M concentrations yielded nanoparticles of 7.22-17.06 nm size, whereas 9 and $10 \times 10^{-3} \mathrm{M} \mathrm{AgNO}_{3}$ concentrations produced 45.93 and $62.12 \mathrm{~nm}$ sized NPs, respectively. This indicates that when the $\mathrm{AgNO}_{3}$ concentration was increased the functional groups available for the reaction were lacking. ${ }^{[216]}$ Gudikandula et al. reported that $15 \mathrm{~nm}$ size silver nanoparticles were synthesized within 12-48 $\mathrm{h}$ (reduction time) by using the biomass of the fungus, Ganoderma enigmaticum (3.9-5.2 g/100 mL solution) in $\mathrm{AgNO}_{3}$ at $60 \mu \mathrm{L}$ of $1.5 \times 10^{-3} \mathrm{M}$ concentrations. ${ }^{[217]}$ The synthesized Ag NPs caused strong antimicrobial effects against B. subtilis, S. aureus, M. luteus, B. cereus, B. megaterium, E. coli, E. aerogens, K. pneumonia, P. vulgaris, P. aeruginosa, and S. paratyphi. ${ }^{[17]}$

\section{Possible Mechanisms of the Antimicrobial Activity of Nanoparticles}

Limited work has been done on the mode and mechanism of NP action as an antimicrobial agent. The studies that investigate this aspect are largely confined to the NPs of silver, gold, and zinc oxide. The data to date are conflicting and differ with the NP type and the species strain studied. ${ }^{[218]}$ However, there are some general ideas emerging that we summarize in the following sections.

\subsection{NP Decomposition into Metal lons}

While acting on the microorganisms, the NPs may revert to the predecessor state, i.e., the ionic form. ${ }^{[219]}$ This would allow for all metal ion specific chemistry to occur, potentially enhanced due to the high localized ion concentration from the NP delivery. Feng et al. reported that the AgNPs decomposing into silver ions, is what caused the antimicrobial effect on the bacterial cells. ${ }^{[220]}$ Silver ion release from AgNPs was also studied by others, showing that this process also depends on the medium. ${ }^{[221]}$ The silver ions readily enter the bacterial cells, causing damage to the cell and inhibited several vital functions. ${ }^{[222,223]}$ Besides, inducing other abnormalities, the silver ions, while inside the cell, possibly inhibited the respiratory enzymes. Silver and other soft metal ions may also act upon the thiol groups of the bacterial enzymes and cause their inactivation. Silver ions are furthermore discussed not only to interact with the cell wall and with N-, O-, and S-donor atoms of proteins, but also to replace protons in the DNA hydrogen bonds, holding the double-helix together, thus inhibiting cell replication as a possibility-a hypothesis yet to be proven. ${ }^{[119,120]}$

Lewis acid-base reactions may be an important mechanism that may operate in the antimicrobial action of NPs in a mechanism similarly reviewed by Lemire et al. for the free metal ions. ${ }^{[120]}$ A strong acid reacts with a strong base, similarly, a soft acid interacts with a soft base. Sulfur and phosphorus are frequently found in the cell as sulfides and phosphates, respectively, and are Lewis basic in nature, whereas silver is a Lewis acid. These soft bases and soft acids react together, e.g., in vital proteins, and result in their inactivation and subsequent death of the cell. ${ }^{[224]}$ Depending on how the atoms are presented on the particle, AgNPs may also react with the DNA. ${ }^{[25,226]}$ Since phosphate is a major component in the backbone of DNA, the AgNPs may react with these anionic bases, leading to structural alterations of the DNA potentially leading to changes in transcription and translation. ${ }^{[222]}$ As a result, cell growth and replication may function abnormally, leading to less fit microorganism. Yet, to date there does not seem to be evidence that silver has a mutating effect to the DNA directly.

\subsection{Reactive Oxygen Species (ROS)}

Silver ion exposure to cells may generate ROS. ${ }^{[227]}$ It has been suggested that the silver ions disrupt $[\mathrm{Fe}-\mathrm{S}]$ clusters in respiratory enzymes releasing the Fe which then can catalyze Fenton reactions leading to ROS. ${ }^{[228]}$ Yet, one does not always see ROS 
production upon silver exposure ${ }^{[28]}$ and some groups have not observed Fe release. ${ }^{[227]}$ This suggests that microbial strain, growth conditions, metal speciation, and the ROS sensor used in detection lead to different outcomes. Although not all metal atoms catalyze Fenton and subsequent Haber-Weiss reactions, as NPs have different properties from the free ions, at this time we cannot rule out that some transition metal NPs may also cause intercellular generation of ROS such as $\mathrm{H}_{2} \mathrm{O}_{2}, \mathrm{OH}^{*}$, and $\mathrm{O}_{2}{ }^{--}$. The $\mathrm{H}_{2} \mathrm{O}_{2}$ is highly damaging to living cells. The UV and visible light activate TiO and ZnO NPs, and as a result, ROS species are generated. The negatively charged ROS likely remain on the cell surface, as they do not penetrate the cell membrane. However, positively charged ROS, i.e., protonated $\mathrm{H}_{2} \mathrm{O}_{2}$ can penetrate the membrane. ${ }^{[229]}$ Although $\mathrm{Zn}^{2+}$ does not lead to intracellular ROS production, ${ }^{[228]}$ the ZnO NPs have been reported to generate ROS in C. jejuni, a Gram-negative bacterium. ${ }^{[202]}$

\subsection{Specific Cellular Process Affected}

\subsubsection{Disruption of the Cell Membrane Integrity}

The AgNPs can penetrate the cell wall of the bacteria by disruption of the wall. ${ }^{[222,223]}$ The particles first adhere to the surface and cause aberrations on the cell membrane. The aberrations may affect the permeability of the membrane to an extent that may lead to cell death. When aberrations are formed nearby each other, they may coalesce forming micropits on the surface of the cell in which NPs may subsequently accumulate. The aberrations on the bacterial cell wall caused by AgNPs may also be formed by ROS, which has been suggested by electron spin resonance spectroscopy studies. ${ }^{[230]}$ At this time one cannot define if this effect is specific to NPs or from the silver ions released locally.

\subsubsection{Signal Transduction Disturbance}

NPs may also interfere in the signal transduction in the exposed bacterial cells. ${ }^{[231]}$ One of the major factors in the signal transduction is the phosphorylation of proteins. When the cells of Gramnegative bacteria were exposed to AgNPs, dephosphorylation took place on the tyrosine residues. ${ }^{[232]}$ As a result of this, signal transduction was disturbed, and growth of the bacterial cell was ceased. Overall signaling processes have not been specifically investigated in response to NPs, and specific hits in omic studies have not highlighted interference with response coupling.

\subsubsection{Chemotaxis and Motility}

Chemotaxis and motility are important characteristics through which the bacteria respond quickly to the chemical changes in the altered environment. Both these characteristics are regulated by genes, in which signaling across the cell is crucial. In the cell membrane of bacteria, the sensory receptor proteins are encoded by the genes tar, str, and tap. Likewise, the components of flagella involved in the bacterial motility are produced in the response of the encoding of the genes fliG, fliN, and fliM, whereas the movement signaling is accomplished by encoding genes cheW, cheB, cheY, cheZ, cheR, cheA, and motB. ${ }^{[233]}$ The swarm plate assay has demonstrated that AuNPs influenced the chemotaxis and motility in the bacteria. However, both the characteristics varied with duration of NP treatment. A large swarm colony of $E$. coli was formed in the medium amended with AuNPs within 4 h. ${ }^{[234]}$ However, after 8 and 20 h, E. coli showed slowed motility. The increasing concentration of AuNPs gradually reduced the colony (swarm) size, although at the early stage, the colonies were bigger than the control. This indicates that the bacteria initially respond rapidly to AuNPs, but the motility, which is ATP dependent, could not continue likely due to an exhaustion of energy.

\section{Conclusion}

Microbial synthesis of NPs may play a role in the commercial production of NPs, if some important aspects such as low yield and particle size/shape heterogeneity are worked out. Further, the microbial capping agents may incite some synergism during antimicrobial action, which may partially prevent therapeutic applications of biosynthetic NPs. In general, this ecofriendly method is simpler than chemical approaches, however, the efficiency in terms of quantitative yield, uniformity, and stability of NPs, and the economics of the process still need to be worked out and ascertained. Various organisms were found to be quite versatile in synthesizing metal atom-based NPs, but efficient strains have not yet been identified/categorized for commercial exploitation.

More research is also required to establish, which bioreactor systems will turn out to be more efficient, planktonic or biofilm systems. We may find that both have their use for selected NP features. Some efforts have been made to optimize the conditions to increase the synthesis yield of NPs, but the development of commercial protocols of microbial synthesis methods needs to be driven forward. Further, there is a significant gap of knowledge and understanding on the mechanism(s) involved in the microbial synthesis, and the available insights into the molecular mechanisms are important puzzle pieces on the way of understanding of the bigger picture(s).

The applicational landscape of biogenic NPs is also still in its infancy. The primary application that most studies explore is that of antimicrobial activity where AgNPs show promise and are already in use in some countries. However, comparing the effectiveness is problematic due to diverse assay protocols, growth conditions and strains. For this, we highlight the comments from Duran et al., where specific protocols for NP characterization as well as antimicrobial efficacy in use of standardized strains and methods are necessary. ${ }^{[235]}$ To their recommendations we suggest authors clear information on particle size, shape, polydispersity, and a full disclosure of the associated bioorganic capping material that may or may not influence the antimicrobial activity and specificity.

\section{Future Prospects}

To date, no comparative data are available on cost of production of NPs through chemical versus microbial methods. We assume 
that the most important contributions to cost are: a) materials (precursor and catalyst/biocatalyst); b) capital and operative cost of the reactor; c) downstream processing (separation and stabilization of NPs). For the chemical synthesis, the cost of catalyst is much higher than the biocatalyst and the operative conditions of the chemical synthesis result in higher operative cost for the chemical synthesis. ${ }^{[236]}$ However, the low titer of NPs in the biosynthesis and the presence of biological material in the reactor broth after the biosynthesis require more expensive downstream processing than in the chemical synthesis. Finally, environmental cost and impact of the two processes should be considered. We think that the biosynthesis of NP may result in lower costs for specific environmental and antibacterial applications. ${ }^{[237]}$ However, life cycle analysis and life cycle costing of biosynthetic NP are needed to establish economic feasibility and ecological sustainability of the microbial NP synthesis process. Further, concerted research efforts are needed to develop industrial protocols to commercialize the microbial synthesis techniques. For the fundamental research, a priority toward understanding the molecular mechanisms involved in the synthesis of NPs is needed and not just more reporting of other organisms doing the same thing. Directed careful studies are required to establish the antimicrobial effects of NPs on a wide range of microorganisms; but these experiments must be done with the same strains and protocols in all labs in order to compare results. In vitro and in vivo effects of NPs on saprophytic and symbiotic microorganisms are also needed, so as to exploit the antimicrobial potential of nanomaterials in the plant disease management. With the specific process understood, exploring defined strains versus mixed species as biofilms is key to moving forward to understand antimicrobial efficacies as well as exploitation of bioproduction in biofilm reactors. Research moving forward understanding the microbial ecology of exposure of NPs in the response of the beneficial soil organisms such as phosphatesolubilizing microorganisms, nitrogen-fixing bacteria, mycorrhizal fungi, and organisms such as protozoans and earthworms as well as toxicology studies on higher level organisms including humans. Before utilizing such NPs in high amounts, we need to appreciate the effects on plant growth system(s) and the stability and lifecycle of the NPs to clearly envision any and all potential of environmental contamination concerns.

\section{Acknowledgements}

Support to R.J.T. from Canadian granting agencies of NSERC and CIHR. M.F. appreciates support from the Swiss National Science Foundation. K.M.F. acknowledges support from NCCR Bioinspired Materials.

\section{Conflict of Interest}

The authors declare no conflict of interest.

\section{Authors Contributions}

M.R.K. conceptualized the project. M.R.K., T.F., and F.A. compiled (except molecular mechanism and characterization methods), redrafted, and revised the manuscript. K.M.F., B.G., and M.F. contributed the section on the molecular mechanisms and characterization methods.
K.M.F. and M.F. revised the manuscript. R.J.T. contributed in different sections and helped in updating and editing the manuscript. E.M. contributed the section on biofilms and revised the manuscript.

\section{Keywords}

bacteria, biomineralization, biosynthesis, fungi, metal nanoparticles, molecular mechanisms, nanotechnology

Received: October 23, 2019

Revised: February 15, 2020

Published online: March 17, 2020

[1] B. Ajitha, Y. A. Kumar Reddy, P. S. Reddy, H.-J. Jeon, C. W. Ahn, RSC Adv. 2016, 6, 36171

[2] K. Rahman, S. U. Khan, S. Fahad, M. X. Chang, A. Abbas, W. U. Khan, L. Rahman, Z. U. Haq, G. Nabi, D. Khan, Int. J. Nanomed. 2019, 14, 1401

[3] L.-J. Tian, W.-W. Li, T.-T. Zhu, J.-J. Chen, W.-K. Wang, P.-F. An, L. Zhang, J.-C. Dong, Y. Guan, D.-F. Liu, N.-Q. Zhou, G. Liu, Y.-C. Tian, H.-Q. Yu, J. Am. Chem. Soc. 2017, 139, 12149.

[4] R. L. Kimber, E. A. Lewis, F. Parmeggiani, K. Smith, H. Bagshaw, T. Starborg, N. Joshi, A. I. Figueroa, G. van der Laan, G. Cibin, D. Gianolio, S. J. Haigh, R. A. D. Pattrick, N. J. Turner, J. R. Lloyd, Small 2018, 14, 1703145.

[5] M. R. Khan, T. F. Rizvi, Plant Pathol. J. 2014, 13, 214.

[6] A. R. Shahverdi, S. Minaeian, H. R. Shahverdi, H. Jamalifar, A.-A. Nohi, Process Biochem. 2007, 42, 919.

[7] B. Khodashenas, H. R. Ghorbani, IET Nanobiotechnol. 2016, 10, 158.

[8] P. Singh, Y. J. Kim, H. Singh, C. Wang, K. H. Hwang, M. E.-A. Farh, D. C. Yang, Int. J. Nanomed. 2015, 10, 2567.

[9] R. Chauhan, A. Reddy, J. Abraham, Appl. Nanosci. 2015, 5, 63.

[10] D. Dhanasekaran, S. Latha, S. Saha, N. Thajuddin, A. Panneerselvam, J. Exp. Nanosci. 2013, 8, 579.

[11] S. Z. Naqvi, U. Kiran, A. Jamal, H. Ahmed Ali, Int. J. Nanomed. 2013, 2013, 3187

[12] A. K. Gade, P. Bonde, A. P. Ingle, P. D. Marcato, N. Durán, M. K. Rai, J. Biobased Mater. Bioenergy 2008, 2, 243.

[13] F. Fatima, P. Bajpai, N. Pathak, S. Singh, S. Priya, S. Verma, BMC Microbiol. 2015, 15, 52.

[14] K. Sneha, M. Sathishkumar, J. Mao, I. S. Kwak, Y.-S. Yun, Chem. Eng. J. 2010, 162, 989.

[15] K. Kathiresan, S. Manivannan, M. A. Nabeel, B. Dhivya, Colloids Surf., B 2009, 71, 133.

[16] M. A. Dar, A. Ingle, M. Rai, Nanomed.: Nanotechnol., Biol. Med. 2013, 9, 105.

[17] S. Scandorieiro, L. C. de Camargo, C. A. C. Lancheros, S. F. Yamada-Ogatta, C. V. Nakamura, A. G. de Oliveira, C. G. T. J. Andrade, N. Duran, G. Nakazato, R. K. T. Kobayashi, Front. Microbiol. 2016, 7, 760

[18] S. Senapati, D. Mandal, A. Ahmad, Indian J. Phys. 2004, 78, 101.

[19] P. M. Gopinath, G. Narchonai, D. Dhanasekaran, A. Ranjani, N. Thajuddin, Asian J Pharm. Sci. 2015, 10, 138.

[20] J. L. Graves, M. Tajkarimi, Q. Cunningham, A. Campbell, H. Nonga, S. H. Harrison, J. E. Barrick, Front. Genet. 2015, 6, 42.

[21] S. Neethu, S. J. Midhun, E. K. Radhakrishnan, M. Jyothis, Microb. Pathog. 2018, 116, 263.

[22] D. Philip, Spectrochim. Acta, Part A 2009, 73, 374.

[23] J. Hiremath, V. Rathod, S. Ninganagouda, D. Singh, K. Prema, J. Pure Appl. Microbiol. 2014, 8, 555.

[24] S. Ray, S. Sarkar, S. Kundu, Dig. J. Nanomater. 2011, 6, 1289. 
[25] A. M. Elgorban, A. N. Al-Rahmah, S. R. Sayed, A. Hirad, A. A.-F. Mostafa, A. H. Bahkali, Biotechnol. Biotechnol. Equip. 2016, 30, 299.

[26] A. M. Fayaz, K. Balaji, M. Girilal, R. Yadav, P. T. Kalaichelvan, R. Venketesan, Nanomed.: Nanotechnol., Biol. Med. 2010, 6, 103.

[27] J. Ramyadevi, K. Jeyasubramanian, A. Marikani, G. Rajakumar, A. A. Rahuman, Mater. Lett. 2012, 71, 114

[28] Y. T. Prabhu, K. V. Rao, V. S. Sai, T. Pavani, J. Saudi Chem. Soc. 2017, 21, 180.

[29] S. A. Khan, A. Ahmad, Chem. Eng. J. 2013, 230, 367.

[30] S. Shivaji, S. Madhu, S. Singh, Process Biochem. 2011, 46, 1800.

[31] S. Priyadarshini, V. Gopinath, N. M. Priyadharsshini, D. MubarakAli, P. Velusamy, Colloids Surf., B 2013, 102, 232.

[32] K. Kalimuthu, R. S. Babu, D. Venkataraman, M. Bilal, S. Gurunathan, Colloids Surf., B 2008, 65, 150.

[33] N. Law, S. Ansari, F. R. Livens, J. C. Renshaw, J. R. Lloyd, Appl. Environ. Microbiol. 2008, 74, 7090.

[34] H. Singh, J. Du, T.-H. Yi, Artif. Cells, Nanomed., Biotechnol. 2017, $45,584$.

[35] G. Singh, P. K. Babele, S. K. Shahi, R. P. Sinha, M. B. Tyagi, A. Kumar, J. Microbiol. Biotechnol. 2014, 24, 1354.

[36] D. Arul, G. Balasubramani, V. Balasubramanian, T. Natarajan, P. Perumal, Pathog. Global Health 2017, 111, 367.

[37] R. Thomas, A. P. Nair, S. KR, J. Mathew, R. EK, Appl. Biochem. Biotechnol. 2014, 173, 449.

[38] H. Gandhi, S. Khan, J. Nanomed. Nanotechnol. 2016, 7, 2.

[39] B. Buszewski, V. Railean-Plugaru, P. Pomastowski, K. Rafińska, M. Szultka-Mlynska, P. Golinska, M. Wypij, D. Laskowski, H. Dahm, J. Microbiol., Immunol. Infect. 2018, 51, 45.

[40] J. Subashini, V. G. Khanna, K. Kannabiran, Bioprocess Biosyst. Eng. 2014, 37, 999.

[41] P. P. Desai, C. Prabhurajeshwar, K. R. Chandrakanth, J. Nanostruct. Chem. 2016, 6, 235.

[42] P. Mukherjee, A. Ahmad, D. Mandal, S. Senapati, S. R. Sainkar, M. I. Khan, R. Parishcha, P. V. Ajaykumar, M. Alam, R. Kumar, M. Sastry, Nano Lett. 2001, 1, 515.

[43] R. Sanghi, P. Verma, Bioresour. Technol. 2009, 100, 501.

[44] K. Vahabi, G. A. Mansoori, S. Karimi, Insci. J. 2011, 65.

[45] A. Ahmad, P. Mukherjee, S. Senapati, D. Mandal, M. I. Khan, R. Kumar, M. Sastry, Colloids Surf., B 2003, 28, 313.

[46] R. Devika, S. Elumalai, E. Manikandan, D. Eswaramoorthy, Sci. Rep. 2012, 1, 15.

[47] M. H. El-Rafie, T. I. Shaheen, A. A. Mohamed, A. Hebeish, Carbohydr. Polym. 2012, 90, 915.

[48] A. Ahmad, S. Senapati, M. I. Khan, R. Kumar, M. Sastry, Langmuir 2003, 19, 3550 .

[49] S. De Corte, T. Hennebel, S. Verschuere, C. Cuvelier, W. Verstraete, N. Boon, J. Chem. Technol. Biotechnol. 2011, 86, 547.

[50] S. He, Z. Guo, Y. Zhang, S. Zhang, J. Wang, N. Gu, Mater. Lett. 2007, 61, 3984.

[51] M. I. Husseiny, M. A. El-Aziz, Y. Badr, M. A. Mahmoud, Spectrochim. Acta, Part A 2007, 67, 1003.

[52] R. M. Jarvis, N. Law, I. T. Shadi, P. O’Brien, J. R. Lloyd, R. Goodacre, Anal. Chem. 2008, 80, 6741.

[53] S. S. Shankar, A. Ahmad, M. Sastry, Biotechnol. Prog. 2003, 19, 1627.

[54] a) P. Mukherjee, A. Ahmad, D. Mandal, S. Senapati, S. R. Sainkar, M. I. Khan, R. Ramani, R. Parischa, P. V. Ajayakumar, M. Alam, M. Sastry, R. Kumar, Angew. Chem., Int. Ed. 2001, 40, 3585; b) P. Mukherjee, A. Ahmad, D. Mandal, S. Senapati, S. R. Sainkar, M. I. Khan, R. Ramani, R. Parischa, P. V. Ajayakumar, M. Alam, M. Sastry, R. Kumar, Angew. Chem. 2001, 113, 3697.

[55] M. Gericke, A. Pinches, Gold Bull. 2006, 39, 22.

[56] A. Mourato, M. Gadanho, A. R. Lino, R. Tenreiro, Bioinorg. Chem. Appl. 2011, 2011, 546074.
[57] M. F. Lengke, M. E. Fleet, G. Southam, Langmuir 2006, 22, 2780.

[58] A. Syed, A. Ahmad, Colloids Surf., B 2012, 97, 27.

[59] Y. Konishi, K. Ohno, N. Saitoh, T. Nomura, S. Nagamine, H. Hishida, Y. Takahashi, T. Uruga, J. Biotechnol. 2007, 128, 648.

[60] R. Brayner, H. Barberousse, M. Hemadi, C. Djedjat, C. Yéprémian, T. Coradin, J. Livage, F. Fiévet, A. Couté, J. Nanosci. Nanotechnol. 2007, 7, 2696.

[61] R. C. Kasana, N. R. Panwar, R. K. Kaul, P. Kumar, Environ. Chem. Lett. 2017, 15, 233.

[62] R. Khani, B. Roostaei, G. Bagherzade, M. Moudi, J. Mol. Liq. 2018, $255,541$.

[63] R. Varshney, S. Bhadauria, M. S. Gaur, R. Pasricha, JOM 2010, 62, 102.

[64] S. Shantkriti, P. Rhani, Int. J. Curr. Microbiol. Appl. Sci. 2014, 3, 374.

[65] C. Jayaseelan, A. A. Rahuman, A. V. Kirthi, S. Marimuthu, T. Santhoshkumar, A. Bagavan, K. Gaurav, L. Karthik, K. V. B. Rao, Spectrochim. Acta, Part A 2012, 90, 78.

[66] K. Prasad, A. K. Jha, Nat. Sci. 2009, 1, 129.

[67] C. A. Woolfolk, H. R. Whiteley, J. Bacteriol. 1962, 84, 647.

[68] C. T. Dameron, R. N. Reese, R. K. Mehra, A. R. Kortan, P. J. Carroll, M. L. Steigerwald, L. E. Brus, D. R. Winge, Nature 1989, 338, 596.

[69] R. Y. Sweeney, C. Mao, X. Gao, J. L. Burt, A. M. Belcher, G. Georgiou, B. L. Iverson, Chem. Biol. 2004, 11, 1553.

[70] K. Prasad, A. K. Jha, J. Colloid Interface Sci. 2010, 342, 68.

[71] D. P. Cunningham, L. L. Lundie, Appl. Environ. Microbiol. 1993, $59,7$.

[72] S. A. Kumar, A. A. Ansary, A. Ahmad, M. I. Khan, J. Biomed. Nanotechnol. 2007, 3, 190.

[73] V. Bansal, D. Rautaray, A. Bharde, K. Ahire, A. Sanyal, A. Ahmad, M. Sastry, J. Mater. Chem. 2005, 15, 2583.

[74] J. M. Byrne, N. D. Telling, V. S. Coker, R. A. D. Pattrick, G. van der Laan, E. Arenholz, F. Tuna, J. R. Lloyd, Nanotechnology 2011, 22, 455709.

[75] P. Karfa, S. De, K. C. Majhi, R. Madhuri, P. K. Sharma, in Comprehensive Nanoscience and Nanotechnology, Elsevier, Amsterdam 2019, pp. 123-144.

[76] X. Wang, Y. Feng, P. Dong, J. Huang, Front. Chem. 2019, 7, 671.

[77] C. J. Reckmeier, J. Schneider, A. S. Susha, A. L. Rogach, Opt. Express 2016, 24, A312.

[78] Y.-P. Sun, B. Zhou, Y. Lin, W. Wang, K. A. S. Fernando, P. Pathak, M. J. Meziani, B. A. Harruff, X. Wang, H. Wang, P. G. Luo, H. Yang, M. E. Kose, B. Chen, L. M. Veca, S.-Y. Xie, J. Am. Chem. Soc. 2006, 128, 7756.

[79] G. E. LeCroy, S.-T. Yang, F. Yang, Y. Liu, K. A. S. Fernando, C. E. Bunker, Y. Hu, P. G. Luo, Y.-P. Sun, Coord. Chem. Rev. 2016, $320,66$.

[80] P. G. Luo, F. Yang, S.-T. Yang, S. K. Sonkar, L. Yang, J. J. Broglie, Y. Liu, Y.-P. Sun, RSC Adv. 2014, 4, 10791.

[81] K. A. S. Fernando, S. Sahu, Y. Liu, W. K. Lewis, E. A. Guliants, A. Jafariyan, P. Wang, C. E. Bunker, Y.-P. Sun, ACS Appl. Mater. Interfaces 2015, 7, 8363.

[82] Y. Wang, A. Hu, J. Mater. Chem. C 2014, 2, 6921.

[83] P. G. Luo, S. Sahu, S.-T. Yang, S. K. Sonkar, J. Wang, H. Wang, G. E. LeCroy, L. Cao, Y.-P. Sun, J. Mater. Chem. B 2013, 1, 2116.

[84] J. Li, V. V. Singh, S. Sattayasamitsathit, J. Orozco, K. Kaufmann, R. Dong, W. Gao, B. Jurado-Sanchez, Y. Fedorak, J. Wang, ACS Nano 2014, 8, 11118.

[85] S. Y. Lim, W. Shen, Z. Gao, Chem. Soc. Rev. 2015, 44, 362.

[86] X. Dong, M. Al Awak, N. Tomlinson, Y. Tang, Y.-P. Sun, L. Yang, PLoS One 2017, 12, e0185324.

[87] M. J. Meziani, X. Dong, L. Zhu, L. P. Jones, G. E. LeCroy, F. Yang, S. Wang, P. Wang, Y. Zhao, L. Yang, R. A. Tripp, Y.-P. Sun, ACS Appl. Mater. Interfaces 2016, 8, 10761.

[88] M. L. Liu, B. Bin Chen, C. M. Li, C. Z. Huang, Green Chem. 2019, 21, 449.

[89] F. Lin, C. Li, Z. Chen, Front. Microbiol. 2018, 9, 2697. 
[90] C.-I. Weng, H.-T. Chang, C.-H. Lin, Y.-W. Shen, B. Unnikrishnan, Y.-J. Li, C.-C. Huang, Biosens. Bioelectron. 2015, 68, 1.

[91] S. Zhang, D. Zhang, Y. Ding, J. Hua, B. Tang, X. Ji, Q. Zhang, Y. Wei, K. Qin, B. Li, Analyst 2019, 144, 5497.

[92] S. Li, X. Zhao, Y. Zhang, H. Chen, Y. Liu, BioResources 2020, 21, 78.

[93] M. Hassellöv, J. W. Readman, J. F. Ranville, K. Tiede, Ecotoxicology 2008, 17, 344

[94] A. B. Stefaniak, Metrology and Standardization for Nanotechnology, Wiley-VCH, Weinheim, Germany 2017, pp. 151-174.

[95] P. M. Carvalho, M. R. Felício, N. C. Santos, S. Gonçalves, M. M. Domingues, Front. Chem. 2018, 6, 237.

[96] A. Rautela, J. Rani, M. Debnath (Das), J. Anal. Sci. Technol. 2019, $10,5$.

[97] N. Hérault, J. Wagner, S.-L. Abram, J. Widmer, L. Horvath, D. Vanhecke, C. Bourquin, K. M. Fromm, Int. J. Nanomed. 2020, 2020, 1267.

[98] M. Das Murtey, P. Ramasamy, Modern Electron Microscopy in Physical and Life Sciences, InTech, UK 2016.

[99] E. Akanny, A. Bonhommé, C. Commun, A. Doleans-Jordheim, C. Farre, F. Bessueille, S. Bourgeois, C. Bordes, J. Raman Spectrosc. 2020.

[100] M. M. Modena, B. Rühle, T. P. Burg, S. Wuttke, Adv. Mater. 2019, 1901556.

[101] G. Gahlawat, A. R. Choudhury, RSC Adv. 2019, 9, 12944.

[102] C. Avazeri, R. J. Turner, J. Pommier, J. H. Weiner, G. Giordano, A. Vermeglio, Microbiology 1997, 143, 1181.

[103] K. Kalishwaralal, V. Deepak, S. Ramkumarpandian, H. Nellaiah, G. Sangiliyandi, Mater. Lett. 2008, 62, 4411.

[104] S. Lampis, E. Zonaro, C. Bertolini, D. Cecconi, F. Monti, M. Micaroni, R. J. Turner, C. S. Butler, G. Vallini, J. Hazard. Mater. 2017, 324, 3.

[105] X. Rong-Mullins, M. J. Winans, J. B. Lee, Z. R. Lonergan, V. A. Pilolli, L. M. Weatherly, T. W. Carmenzind, L. Jiang, J. R. Cumming, G. S. Oporto, J. E. G. Gallagher, Metallomics 2017, 9, 1304.

[106] P. Srivastava, M. Kowshik, Archaea 2013, 2013, 732864.

[107] M. Mergeay, S. Monchy, T. Vallaeys, V. Auquier, A. Benotmane, P. Bertin, S. Taghavi, J. Dunn, D. van der Lelie, R. Wattiez, FEMS Microbiol. Rev. 2003, 27, 385.

[108] X. Wei, M. Luo, W. Li, L. Yang, X. Liang, L. Xu, P. Kong, H. Liu, Bioresour. Technol. 2012, 103, 273.

[109] U. Shedbalkar, R. Singh, S. Wadhwani, S. Gaidhani, B. A. Chopade, Adv. Colloid Interface Sci. 2014, 209, 40.

[110] N. I. Hulkoti, T. C. Taranath, Colloids Surf., B 2014, 121, 474.

[111] G. Wang, H. Mitomo, Y. Matsuo, N. Shimamoto, K. Niikura, K. Ijiro, J. Mater. Chem. B 2013, 1, 5899.

[112] M. V. R. Kumari, M. Hiramatsu, M. Ebadi, Free Radical Res. 1998, 29, 93.

[113] N. L. Pacioni, C. D. Borsarelli, V. Rey, A. V. Veglia, in Silver Nanoparticle Applications (Eds: E. I. Alarcon, M. Griffith, K. I. Udekwu), Springer, Cham 2015, pp. 13-46.

[114] A. Banerjee, U. Halder, R. Bandopadhyay, J. Cluster Sci. 2017, 28, 1803.

[115] B. Calderón-Jiménez, M. E. Johnson, A. R. Montoro Bustos, K. E. Murphy, M. R. Winchester, J. R. Vega Baudrit, Front. Chem. 2017, 5, 6 .

[116] J. E. Baldwin, R. M. Adlington, M. Bradley, N. J. Turner, A. R. Pitt, J. Chem. Soc., Chem. Commun. 1989, 978.

[117] D. Creed, Photochem. Photobiol. 1984, 39, 563.

[118] R. A. Edwards, G. Jickling, R. J. Turner, Photochem. Photobiol. 2002, $75,362$.

[119] S. Eckhardt, P. S. Brunetto, J. Gagnon, M. Priebe, B. Giese, K. M. Fromm, Chem. Rev. 2013, 113, 4708.

[120] J. A. Lemire, J. J. Harrison, R. J. Turner, Nat. Rev. Microbiol. 2013, $11,371$.

[121] a) K. Belser, T. Vig Slenters, C. Pfumbidzai, G. Upert, L. Mirolo, K. M. Fromm, H. Wennemers, Angew. Chem., Int. Ed. 2009, 48,
3661; b) K. Belser, T. V. Slenters, C. Pfumbidzai, G. Upert, L. Mirolo, K. M. Fromm, H. Wennemers, Angew. Chem. 2009, 121, 3715.

[122] a) S. Kracht, M. Messerer, M. Lang, S. Eckhardt, M. Lauz, B. Grobéty, K. M. Fromm, B. Giese, Angew. Chem., Int. Ed. 2015, 54, 2912; b) S. Kracht, M. Messerer, M. Lang, S. Eckhardt, M. Lauz, B. Grobéty, K. M. Fromm, B. Giese, Angew. Chem. 2015, 127, 2954.

[123] L. Mirolo, T. Schmidt, S. Eckhardt, M. Meuwly, K. M. Fromm, Chem. - Eur.J. 2013, 19, 1754.

[124] C. M. Völkle, D. Gebauer, H. Cölfen, Faraday Discuss. 2015, 179, 59.

[125] S. I. Vasylevskyi, S. Kracht, P. Corcosa, K. M. Fromm, B. Giese, M. Füeg, Angew. Chem., Int. Ed. 2017, 56, 5926.

[126] J. Xie, J. Y. Lee, D. I. C. Wang, Y. P. Ting, ACS Nano 2007, 1, 429.

[127] V. Chabert, M. Hologne, O. Sénèque, A. Crochet, O. Walker, K. M. Fromm, Chem. Commun. 2017, 53, 6105.

[128] V. da Silva Ferreira, M. E. ConzFerreira, L. M. T. R. Lima, S. Frasés, W. de Souza, C. Sant'Anna, Enzyme Microb. Technol. 2017, 97, 114.

[129] J. R. Lloyd, J. M. Byrne, V. S. Coker, Curr. Opin. Biotechnol. 2011, 22, 509.

[130] A. K. Gade, S. R. Bonde, S. M. Meshram, I. R. Gupta, M. K. Rai, IET Nanobiotechnol. 2013, 7, 28.

[131] S. Durmazel, A. Üzer, B. Erbil, B. Sayın, R. Apak, ACS Omega 2019, 4, 7596.

[132] a) M. Cordes, B. Giese, Chem. Soc. Rev. 2009, 38, 892; b) K. Saito, T. Kikuchi, K. Mukai, H. Sumi, Phys. Chem. Chem. Phys. 2009, 11, 5290.

[133] W. C. Thomas, F. P. Brooks, A. A. Burnim, J.-P. Bacik, J. Stubbe, J. T. Kaelber, J. Z. Chen, N. Ando, Nat. Commun. 2018, 10, 504290.

[134] E. C. Minnihan, D. G. Nocera, J. Stubbe, Acc. Chem. Res. 2013, 46, 2524.

[135] a) J. Gao, P. Müller, M. Wang, S. Eckhardt, M. Lauz, K. M. Fromm, B. Giese, Angew. Chem. Int. Ed. 2011, 50, 1926; b) M. Lauz, S. Eckhardt, K. M. Fromm, B. Giese, Phys. Chem. Chem. Phys. 2012, 14, 13785.

[136] a) M. Wang, J. Gao, P. Müller, B. Giese, Angew. Chem. Int. Ed. Engl. 2009, 48, 3490; b) B. Giese, M. Wang, J. Gao, M. Stoltz, P. Müller, M. Graber, J. Org. Chem. 2009, 74, 3621.

[137] B. Giese, Annu. Rev. Biochem. 2002, 71, 51.

[138] a) B. Giese, J. Amandrut, A. K. Köhler, M. Spormann, B. Giese, Nature 2001, 412, 318; b) B. Giese, B. Carl, T. Carl, T. Carell, C. Behrens, U. Hennecke, O. Schiemann, E. Feresin, Angew. Chem. Int. Ed. 2004, 43, 1747; c) S.-H. Lin, M. Fujitsuka, T. Majima, J. Phys. Chem. B 2016, 120, 660.

[139] S Wang, R. Lawson, P. C. Ray, H Yu, Toxicol. Ind. Health 2011, 27, 547.

[140] J. Jin, X. Ouyang, J. Li, J. Jiang, H. Wang, Y. Wang, R. Yang, Sci. China: Chem. 2011, 54, 1266.

[141] D. Bain, B. Paramanik, A. Patra, J. Phys. Chem. C 2017, 121, 4608.

[142] A. S. Reddy, C.-Y. Chen, C.-C. Chen, J.-S. Jean, H.-R. Chen, M.-J. Tseng, C.-W. Fan, J.-C. Wang, J. Nanosci. Nanotechnol. 2010, 10, 6567 .

[143] a) G. Reguera, K. D. McCarthy, T. Mehta, J. S. Nicoll, M. T. Tuominen, D. R. Lovley, Nature 2005, 435, 1098; b) L. Morgado, A. P. Fernandes, J. M. Dantas, M. A. Silva, C. A. Salgueiro, Biochem. Soc. Trans. 2012, 40, 1295.

[144] L. Shi, D. J. Richardson, Z. Wang, S. N. Kerisit, K. M. Rosso, J. M. Zachara, J. K. Fredrickson, Environ. Microbiol. Rep. 2009, 1, 220.

[145] A. P. Fernandes, T. C. Nunes, C. M. Paquete, C. A. Salgueiro, Biochem. J. 2017, 474, 797.

[146] H. C. Watanabe, Y. Yamashita, H. Ishikita, Proc. Natl. Acad. Sci. USA 2017, 114, 2916.

[147] S. Seeliger, R. Cord-Ruwisch, B. Schink, J. Bacteriol. 1998, 180, 3686.

[148] Y. Xiao, E. Zhang, J. Zhang, Y. Dai, Z. Yang, H. E. M. Christensen, J. Ulstrup, F. Zhao, Sci. Adv. 2017, 3, e1700623.

[149] K. Inoue, X. Qian, L. Morgado, B.-C. Kim, T. Mester, M. Izallalen, C. A. Salgueiro, D. R. Lovley, Appl. Environ. Microbiol. 2010, 76, 3999. 
[150] G. T. Feliciano, R. J. Steidl, G. Reguera, Phys. Chem. Chem. Phys. 2015, 17, 22217.

[151] Y. Tan, R. Y. Adhikari, N. S. Malvankar, J. E. Ward, T. L. Woodard, K. P. Nevin, D. R. Lovley, $m$ Bio 2017, 8, e02203.

[152] J. G. Nathanael, L. F. Gamon, M. Cordes, P. R. Rablen, T. Bally, K. M. Fromm, B. Giese, U. Wille, ChemBioChem 2018, 19, 922.

[153] D. J. Filman, S. F. Marino, J. E. Ward, L. Yang, Z. Mester, E. Bullitt, D. R. Lovley, M. Strauss, Commun. Biol. 2019, 2, 219.

[154] S.-W. Li, X. Zhang, G.-P. Sheng, Environ. Sci. Pollut. Res. 2016, 23, 8627.

[155] V. Chabert, L. Babel, M. P. Füeg, M. Karamash, E. S. Madivoli, N. Herault, J. M. Dantas, C. A. Salgueiro, B. Giese, K. M. Fromm, Angew. Chem. Int. Ed. 2020, https://doi.org/10.1002/ anie.201914873.

[156] H.-C. Flemming, J. Wingender, U. Szewzyk, P. Steinberg, S. A. Rice, S. Kjelleberg, Nat. Rev. Microbiol. 2016, 14, 563.

[157] P. E. Bell, A. L. Mills, J. S. Herman, Appl. Environ. Microbiol. 1987, 53, 2610.

[158] E. Marsili, H. Beyenal, L. Di Palma, C. Merli, A. Dohnalkova, J. E. Amonette, Z. Lewandowski, Environ. Sci. Technol. 2007, 41, 8349.

[159] A. J. Kora, R. B. Sashidhar, J. Antibiot. 2015, 68, 88.

[160] J. Tang, Y. Wu, S. Esquivel-Elizondo, S. J. Sørensen, B. E. Rittmann, Trends Biotechnol. 2018, 36, 1171.

[161] A. H. Tanzil, S. T. Sultana, S. R. Saunders, L. Shi, E. Marsili, H. Beyenal, Enzyme Microb. Technol. 2016, 95, 4.

[162] S. Kalathil, J. Lee, M. H. Cho, Green Chem. 2011, 13, 1482.

[163] A. A. Lima de Silva, M. A. R. de Carvalho, S. A. L. de Souza, P. M. T. Dias, R. G. da Silva Filho, C. S. de Meirelles Saramago, C. A. de Melo Bento, E. Hofer, Braz. J. Microbiol. 2012, 43, 1620.

[164] D. Keogh, L. N. Lam, L. E. Doyle, A. Matysik, S. Pavagadhi, S. Umashankar, P. M. Low, J. L. Dale, Y. Song, S. P. Ng, C. B. Boothroyd, G. M. Dunny, S. Swarup, R. B. H. Williams, E. Marsili, K. A. Kline, mBio 2018, 9, https://doi.org/10.1128/mBio.00626-17.

[165] S. Shoeibi, M. Mashreghi, J. Trace Elem. Med. Biol. 2017, $39,135$.

[166] Y. Aktan, S. Tan, B. Icgen, Environ. Monit. Assess. 2013, 185, 5285.

[167] V. L. da Silva, N. C. Caçador, C. dos, S. F. da Silva, C. O. Fontes, G. D. Garcia, J. R. Nicoli, C. G. Diniz, Microbes Environ. 2012, 27, 179.

[168] M. B. Lohse, M. Gulati, A. D. Johnson, C. J. Nobile, Nat. Rev. Microbiol. 2018, 16, 19.

[169] J. V. Desai, A. P. Mitchell, D. R. Andes, Cold Spring Harbor Perspect. Med. 2014, 4, a019729.

[170] J. J. Harrison, M. Rabiei, R. J. Turner, E. A. Badry, K. M. Sproule, H. Ceri, FEMS Microbiol. Ecol. 2006, 55, 479.

[171] J. J. Harrison, H. Ceri, J. Yerly, M. Rabiei, Y. Hu, R. Martinuzzi, R. J. Turner, Appl. Environ. Microbiol. 2007, 73, 4940.

[172] T. J. Battin, K. Besemer, M. M. Bengtsson, A. M. Romani, A. I. Packmann, Nat. Rev. Microbiol. 2016, 14, 251.

[173] K. Zhou, Y. Hu, L. Zhang, K. Yang, D. Lin, Sci. Rep. 2016, 6, 32998.

[174] A. Feurtet-Mazel, S. Mornet, L. Charron, N. Mesmer-Dudons, R. Maury-Brachet, M. Baudrimont, Environ. Sci. Pollut. Res. 2016, 23,4334 .

[175] A. Schröfel, G. Kratošová, M. Bohunická, E. Dobročka, I. Vávra, J. Nanopart. Res. 2011, 13, 3207.

[176] J. J. Harrison, H. Ceri, C. A. Stremick, R. J. Turner, Environ. Microbiol. 2004, 6, 1220.

[177] J. M. L. Chang, D. J. McCanna, L. N. Subbaraman, L. W. Jones, Optom. Vis. Sci. 2015, 92, 506.

[178] S. Golby, H. Ceri, L. L. R. Marques, R. J. Turner, Microb. Ecol. 2014, 68,70 .

[179] S. Siemer, A. Hahlbrock, C. Vallet, D. J. McClements, J. Balszuweit, J. Voskuhl, D. Docter, S. Wessler, S. K. Knauer, D. Westmeier, R. H. Stauber, NPJ Sci. Food 2018, 2, 22.

[180] M. H. U. Bhuiyan, R. Saidur, M. A. Amalina, R. M. Mostafizur, A. Islam, Proc. Eng. 2015, 105, 431.
[181] M. Planchon, T. Léger, O. Spalla, G. Huber, R. Ferrari, PLoS One 2017, 12, e0178437.

[182] Y. Li, D. Yang, S. Wang, C. Li, B. Xue, L. Yang, Z. Shen, M. Jin, J. Wang, Z. Qiu, Molecules 2018, 23, 606.

[183] J. A. Lemire, L. Kalan, A. Bradu, R. J. Turner, Antimicrob. Agents Chemother. 2015, 59, 4031.

[184] P. Logeswari, S. Silambarasan, J. Abraham, J. Saudi Chem. Soc. 2015, 19, 311.

[185] H. Tian, Q. Liao, M. Liu, J. Hou, Y. Zhang, J. Liu, Int. J. Clin. Exp. Med. 2015, 8, 5794.

[186] M. R. Khan, M. Akram, in Biogenic Nano-Particles and Their Use in Agro-Ecosystems (Ed: M. Ghorbanpour), Springer, Cham 2020.

[187] P. Singh, Y. J. Kim, H. Singh, R. Mathiyalagan, C. Wang, D. C. Yang, J. Nanomater. 2015, 2015, 1469.

[188] P. Singh, H. Singh, Y. J. Kim, R. Mathiyalagan, C. Wang, D. C. Yang, Enzyme Microb. Technol. 2016, 86, 75.

[189] S. Sathiyavimal, S. Vasantharaj, D. Bharathi, M. Saravanan, E. Manikandan, S. S. Kumar, A. Pugazhendhi, J. Photochem. Photobiol., B 2018, 188, 126.

[190] J. Pasquet, Y. Chevalier, J. Pelletier, E. Couval, D. Bouvier, M.-A. Bolzinger, Colloids Surf., A 2014, 457, 263.

[191] R. Bryaskova, D. Pencheva, S. Nikolov, T. Kantardjiev, J. Chem. Biol. 2011, 4, 185.

[192] M. Vijayakumar, K. Priya, F. T. Nancy, A. Noorlidah, A. B. A. Ahmed, Ind. Crops Prod. 2013, 41, 235.

[193] Jena, Mohanty, Mallick, Jacob, A. Sonawnae, Int. J. Nanomed. 2012, 2012, 1805.

[194] X.-F. Zhang, W. Shen, S. Gurunathan, Int. J. Mol. Sci. 2016, 17, 1603.

[195] R. Thomas, A. Janardhanan, R. T. Varghese, E. V. Soniya, J. Mathew, E. K. Radhakrishnan, Braz. J. Microbiol. 2014, 45, 1221.

[196] D. M. Rudakiya, K. Pawar, 3 Biotech 2017, 7, 92.

[197] A. E. Mohammed, Asian Pac. J. Trop. Biomed. 2015, 5, 382.

[198] W. Salem, D. R. Leitner, F. G. Zingl, G. Schratter, R. Prassl, W. Goessler, J. Reidl, S. Schild, Int. J. Med. Microbiol. 2015, 305, 85.

[199] B. S Hungund, J. Nanomed. Nanotechnol. 2015, 6, 2.

[200] H. Erjaee, H. Rajaian, S. Nazifi, Adv. Nat. Sci. Nanosci. Nanotechnol. 2017, 8, 025004.

[201] Y. Xie, Y. He, P. L. Irwin, T. Jin, X. Shi, Appl. Environ. Microbiol. 2011, $77,2325$.

[202] P. Tangwatcharin, S. Chanthachum, P. Khopaibool, M. W. Griffiths, J. Food Prot. 2006, 69, 2747.

[203] R. K. Shah, F. Boruah, N. Parween, Int. J. Curr. Microbiol. Appl. Sci 2015, 4, 444

[204] R. Dobrucka, J. Długaszewska, Saudi J. Biol. Sci. 2016, 23, 517.

[205] S. Mahmoodi, A. Elmi, S. H. Nezhadi, J. Mol. Pharm. Org. Process Res. 2018, 6, 140.

[206] N.-Y. Lee, W.-C. Ko, P.-R. Hsueh, Front. Pharmacol. 2019, 10, 1153.

[207] R. Singh, U. U. Shedbalkar, S. A. Wadhwani, B. A. Chopade, Appl. Microbiol. Biotechnol. 2015, 99, 4579.

[208] S. Shaikh, N. Nazam, S. M. D. Rizvi, K. Ahmad, M. H. Baig, E. J. Lee, I. Choi, Int. J. Mol. Sci. 2019, 20, 2468.

[209] E. Katz, I. Willner, Angew. Chem., Int. Ed. 2004, 43, 6042.

[210] A. Rai, A. Prabhune, C. C. Perry, J. Mater. Chem. 2010, 20, 6789.

[211] J. Li, H. Sang, H. Guo, J. T. Popko, L. He, J. C. White, O. P. Dhankher, G. Jung, B. Xing, Nanotechnology 2017, 28, 155101.

[212] L. He, Y. Liu, A. Mustapha, M. Lin, Microbiol. Res. 2011, 166, 207.

[213] J. Mittal, A. Singh, A. Batra, M. M. Sharma, Braz. Arch. Biol. Technol. 2016, 59, https://doi.org/10.1590/1678-4324-2016150508.

[214] C. Krishnaraj, R. Ramachandran, K. Mohan, P. T. Kalaichelvan, Spectrochim. Acta, Part A 2012, 93, 95.

[215] P. Phanjom, G. Ahmed, Adv. Nat. Sci. Nanosci. Nanotechnol. 2017, 8, 045016.

[216] M. Guilger-Casagrande, R. de Lima, Front. Bioeng. Biotechnol. 2019, 7, 287.

[217] K. Gudikandula, P. Vadapally, M. A. S. Charya, OpenNano 2017, 2, 64. 
[218] J. H. Niazi, M. B. Gu, Atmospheric and Biological Environmental Monitoring, Springer, Dordrecht, The Netherlands 2009, pp. 193-206.

[219] I. Khan, K. Saeed, I. Khan, Arabian J. Chem. 2019, 12, 908.

[220] Y.-G. Yuan, Q.-L. Peng, S. Gurunathan, Int. J. Mol. Sci. 2017, $18,569$.

[221] M. Priebe, J. Widmer, N. S. Löwa, S.-L. Abram, I. Mottas, A.-K. Woischnig, P. S. Brunetto, N. Khanna, C. Bourquin, K. M. Fromm, Nanomed.: Nanotechnol., Biol. Med. 2017, 13, 11.

[222] T. C. Dakal, A. Kumar, R. S. Majumdar, V. Yadav, Front. Microbiol. 2016, 7, 1831.

[223] Y. Qing, L. Cheng, R. Li, G. Liu, Y. Zhang, X. Tang, J. Wang, H. Liu, Y. Qin, Int. J. Nanomed. 2018, 13, 3311.

[224] J. R. Morones, J. L. Elechiguerra, A. Camacho, K. Holt, J. B. Kouri, J. T. Ramírez, M. J. Yacaman, Nanotechnology 2005, 16, 2346.

[225] S. Nallanthighal, C. Chan, T. M. Murray, A. P. Mosier, N. C. Cady, R. Reliene, Nanotoxicology 2017, 11, 996.

[226] S. Hu, T. Yi, Z. Huang, B. Liu, J. Wang, X. Yi, J. Liu, Mater. Horiz. 2019, 6, 155 .

[227] O. Gordon, T. V. Slenters, P. S. Brunetto, A. E. Villaruz, D. E. Sturdevant, M. Otto, R. Landmann, K. M. Fromm, Antimicrob. Agents Chemother. 2010, 54, 4208.
[228] J. J. Harrison, V. Tremaroli, M. A. Stan, C. S. Chan, C. Vacchi-Suzzi, B. J. Heyne, M. R. Parsek, H. Ceri, R. J. Turner, Environ. Microbiol. 2009, 11, 2491.

[229] A. Phaniendra, D. B. Jestadi, L. Periyasamy, Indian J. Clin. Biochem. 2015, 30, 11.

[230] S. Ninganagouda, V. Rathod, D. Singh, J. Hiremath, A. K. Singh, J. Mathew, M. Ul-Haq, Biomed Res. Int. 2014, 2014, 753419.

[231] J.-M. Exbrayat, E. N. Moudilou, E. Lapied, J. Nanotechnol. 2015, $2015,861092$.

[232] S. Shrivastava, T. Bera, A. Roy, G. Singh, P. Ramachandrarao, D. Dash, Nanotechnology 2007, 18, 225103.

[233] T. J. Muff, G. W. Ordal, Mol. Microbiol. 2008, 70, 1054.

[234] Y. Cui, Y. Zhao, Y. Tian, W. Zhang, X. Lü, X. Jiang, Biomaterials 2012, 33, 2327.

[235] N. Durán, G. Nakazato, A. B. Seabra, Appl. Microbiol. Biotechnol. 2016, 100, 6555.

[236] F. Peng, H. Yin, S.-L. Cao, W.-Y. Lou, Advances in Enzyme Technology, Elsevier, Amsterdam 2019, pp. 153-168.

[237] A. Schröfel, G. Kratošová, I. Šafařík, M. Šafaříková, I. Raška, L. M. Shor, Acta Biomater. 2014, 10, 4023.

[238] M. R. Khan, V. Adam, T. F. Rizvi, B. Zhang, F. Ahamad, I. Josko, Y. Zhu, M. Yang, M. Mao, Small 2019, 15, 1901794. 